\title{
Stone Age transitions. Neolithization in central Scandinavia
}

\author{
Helena Knutsson and Kjel Knutsson \\ Department of Archaeology and ancient History, Uppsala University, S \\ Helena.Knutsson@arkeologi.uu.se, Kjel.Knutsson@arkeologi.uu.se
}

\begin{abstract}
A summary of a series of individual research projects focused on the processes from the Mesolithic to the Late Neolithic in central Scandinavia. The projects were embeded in the "Coast to Coast project". The historicity in this process was emphasised.

IZVLEČEK - V članku povzemamo serijo posameznih raziskovalnih projektov, ki se nanašajo na spremembe od mezolitika do poznega neolitika v srednji Skandinaviji. Zajeti so v projekt "Od obale do obale". Poseben poudarek je na zgodovinskih dejstvih teh sprememb.
\end{abstract}

KEY WORDS - Mesolithic; Neolithic; hunter-gatherers; farmers; neolithization; central Scandinavia

\section{INTRODUCTION}

This paper is a summary of the Uppsala part of a series of individual research projects in connection with a joint research program carried out in collaboration with the departments of archaeology in Uppsala, Göteborg, Lund, and Stockholm. The project: "Coast to Coast - Stone Age Societies in Change" was launched in 1998 and is financed by the Tercentenary Foundation of The Bank of Sweden. It covers cultural development in Central Scandinavia in the early part of the Holocene, from the deglaciation $(8000 \mathrm{cal} \mathrm{BC})$ to the Late Neolithic $(1800 \mathrm{cal} \mathrm{BC})$. Our part of the project (including 3 projects from Lund and Stockholm Universities) has mainly been organized as a series of $\mathrm{PhD}$ works (seven in all) and deals essentially with archaeological evidence from the eastern part of central Sweden, where processes of cultural change in relation to Neolithization at the Mesolithic-Neolithic transition (F. Hallgren, C. Lidström-Holmberg, A. Sundström and C. Lindgren) and the expansion of a full Neolithic economy in the Late Neolithic (J. Apel and P. Lekberg) are studied. In the PhD project by Per Johansson from Lund University, a critical discussion of archaeological thinking in relation to the Neolithization debate is car- ried out, as seen from the point of view of human ecology. Apart from the 7 individual PhD projects, two research projects covering a more general discussion of cultural change and within a broader spatial perspective have been carried out by two senior researchers at Uppsala (H. Knutsson and K. Knutsson). Helena Knutsson has concentrated on the problem of the "Neolithic concept" and the processes related to its introduction in southern Scandinavia c 3900 cal BC, whereas Kjel Knutsson, basing his work on a theory of structuration, has tried to throw light on the historical roots of the "cultural substrate" that formed the socio-spatial preconditions for the Neolithization in central Scandinavia.

\section{THE SETTING}

Eastern central Sweden consists of the provinces of Uppland, Västmanland, Närke and Södermanland. The Swedish capital, Stockholm, is situated in the eastern part of the region (Fig. 1). During most of the Stone Age, eastern central Sweden consisted of a wide archipelago (compare Fig. 4) delimited by 
the surrounding landmasses of Kolmården and Tiveden to the south, Kilsbergen to the east, and the higher lying areas of northern Svealand to the north. To the north, the area ends in a cultural and geographically important border called "Limes Norlandicus". This border between northern and central Sweden, as will be shown in the following texts, may have been an important divide between hunters and gatherers in the north and farmers and stockbreeders in the south throughout the Stone Age, Bronze Age and Iron Age. Isostatic rebound raised an archipelago from the sea after the retreat of the ice ten thousand years ago, forming large islands and adjoining land areas. The landscape is transacted by glacial eskers surrounded by sandy areas, bedrock formations polished smooth by glacial movements, and postglacial clay in the valley bottoms. This changing landscape of small and large islands formed the basis for the colonization of the area by hunter-gatherers as early as the Preboral (7500 cal BC) (Knutsson et al. 1999).

Hundreds of Mesolithic sites found through surveys by the National Board of Antiquities over the last 70

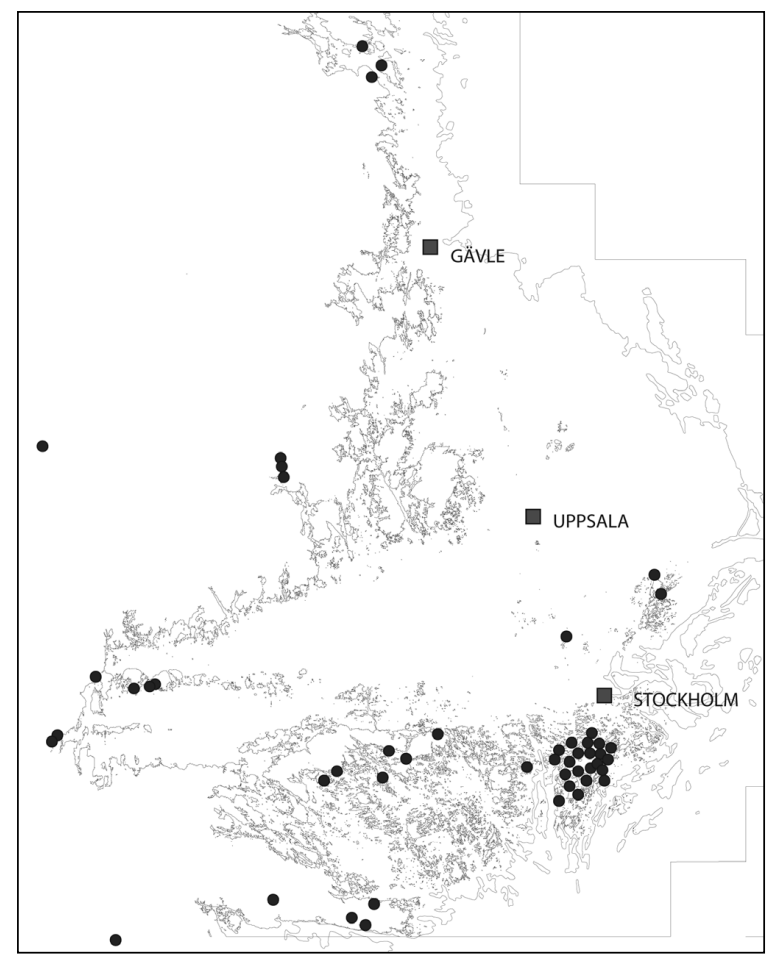

Fig. 2. All Mesolithic sites excavated in Eastern Central Sweden between the years 1935-1996. They are dated to the time span $c 7500 \mathrm{cal} B C$ to $c$ 4000 cal BC and thus almost cover the entire period from the deglaciation to the neolithization. The sites are shown in relation to the shoreline $c$. 5000 cal BC. The concentration of sites south of Stockholm is due to recent building activities.

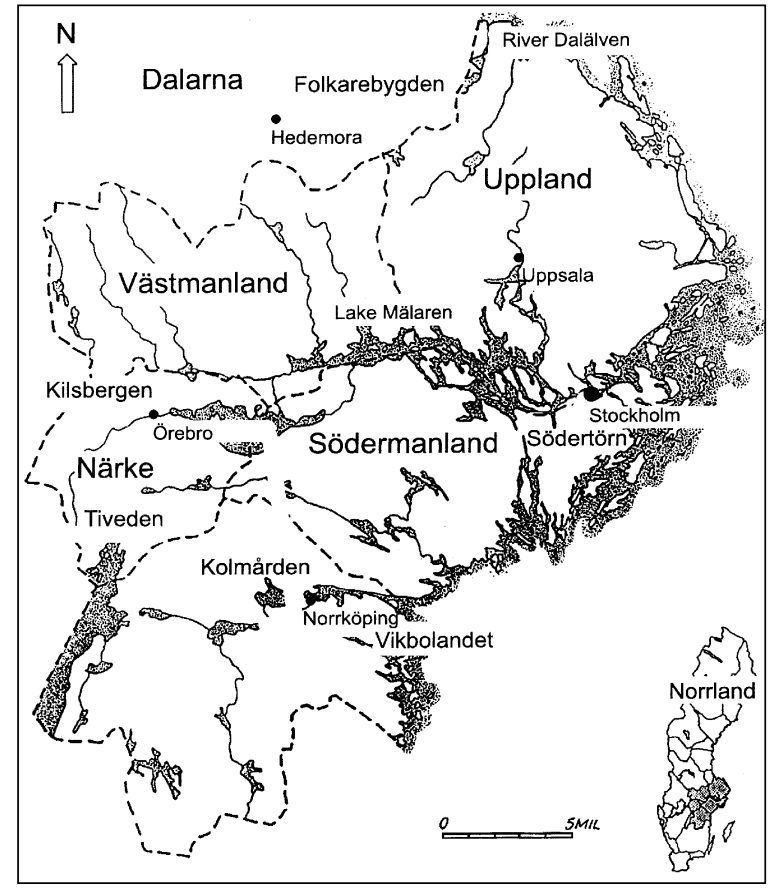

Fig. 1. Map of the discussed area, Eastern Central Sweden, and its surroundings, showing the place names and localities mentioned (after Boas 1999. Fig. 1).

years are known in the area. All together, 55 sites have been excavated, primarily as rescue excavations (Fig. 2). No thorough analysis has been carried out so far, but in a recent paper (Knutsson et al. 1999) it has been shown that the Mesolithic was characterized by sites situated by the sea, with an economy geared mainly towards the exploitation of marine resources such as seal and fish. Some inland sites, with elk and deer bones may indicate a seasonal movement based on inland-coast commuting. Detailed analyses of some sites indicate that at least the Middle and Late Mesolithic must be characterized as a logistic settlement system (Knutsson \& Melchert in press). So far, no Mesolithic graves have been found or excavated in this part of Scandinavia. The material culture shows low variability; quartz is the principle raw material of flaked tools, and greenstone for axes. In the Early and Middle Mesolithic, imported flints from south and west Scandinavia, mainly in the form of micro-blades, are present. In the Late Mesolithic there is a change in the lithic industry from bipolar-on-anvil to a platform technique in quartz, as well as the introduction of four-sided, polished axes and transverse arrowheads (Fig. 3). A change in the type of and variation in settlements also occurs at this time.

The Neolithic occupation is known from thousands of stray finds and hundreds of surveyed sites. Only 
about 25 sites from the Early Neolithic TRB culture have so far been excavated (Fig. 4). The Funnel Beaker Culture (TRB) in the area is mainly characterized by two types of site: those on the coast which are dominated by the remains of fishing and seal hunting, and inland farmsteads, dominated by the remains of domestic animals such as cattle, sheep and goat, and cultivated plants: wheat, barley, peas, beans, and vinegrapes. The same types of archaeological material (funnelbeakers, polygonal battle axes, thin-butted axes, flint industry, sandstone querns, etc (Figs. 5,

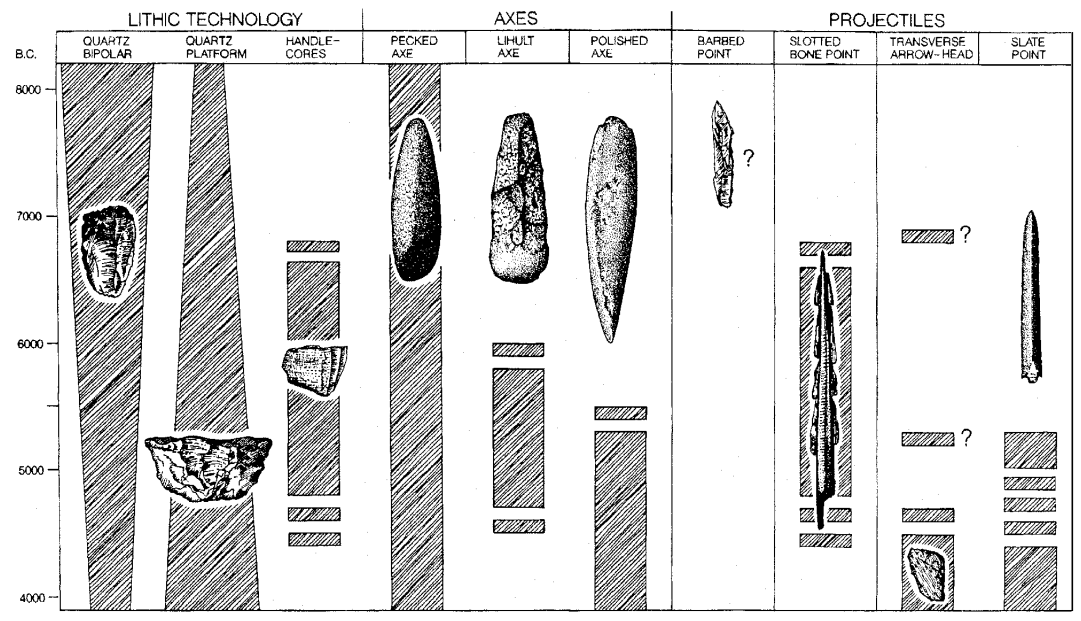

Fig. 3. Tentative chronological scheme for the Mesolithic in Eastern Central Sweden. Slate points, transverse arrowheads and polished greenstone axes are characteristic of the period 4500-4000 cal BC, indicating a clear change in material culture.

$20 \mathrm{a}$ an b), occur in both contexts. Small huts and burials are the settings of the coastal finds (Fig. 20c); houses with attached sacrificial fens relate to the inland sites. The relative dietary importance of domesticated products compared to wild resources cannot be estimated on the basis of present data.

Regarding the Pitted Ware Culture (PWC), which represents a change in the TRB society in this area towards more hunting and gathering in the Early Middle Neolithic, large amounts of pottery and a faunal assemblage dominated by seal bones characterizes the sites in the coastal area. As to the material culture, apart from the characteristic pottery, knapped quartz dominates; some imported flints and locally produced pecked axes are reminiscent of Mesolithic axes. In the later Middle Neolithic, graves and stray finds from the Battle Axe Culture are found. Only one settlement from this period was excavated, with meagre results. Whether the PWC and the BAC represent of represent cultural dualism or intercultural variation in the Late Middle Neolithic in this area is still a matter of debate.

The Late Neolithic shows a homogenisation of material culture, and the expansion and continuation of farming settlement, following the Battle Axe Tradition (Corded Ware Culture). Although conceivable changes appear in the fashions of material culture, settlements and everyday behaviour seem to continue along the same lines. The cultural process related to this general change in the economy and material culture, has been the main topic of the Coast to Coast project. At the political level we see a change toward a stratified society in the Late Neolithic, but what is more important, the process of change seems to bear on long-term historical structures, a past made active in the construction of new ideologies in periods of paradigmatic change.

\section{THE APPROPRIATION OF THE PAST}

In one of the Coast to Coast research projects formed around a theory of historical structuration, Kjel Knutsson tries to show how the historical circumstances related to the speed and direction of the melting ice at the beginning of the Holocene formed the substrate for the large scale social structures that seem to have been decisive for the spread of the Neolithic way of life in southern Scandinavia at the beginning of the fourth millennium cal $\mathrm{BC}$, and a cultural distinction in the northern part of Scandinavia at the same time. The latter process is seen as formed through a process of ethnicity.

As the ice melted from south to north at a speed of roughly $500 \mathrm{~km}$ every 500 years, hunters and gatherers colonized new, uninhabited territories. The colonizers met a "land without history", open to colonisation by people, animals and vegetation, creating opportunities for "a construction of historical references" by ordering and name-giving, logical to a basic cosmology. Based on theories of social and ethnic processes related to the colonization of new land, it can be shown through radiocarbon dated pioneering sites and a diachronic analysis of traditional archaeological patterning, that local group formation and processes establishing local autonomy occurred at roughly every $500 \mathrm{~km}$ (Fig. 6). The early 


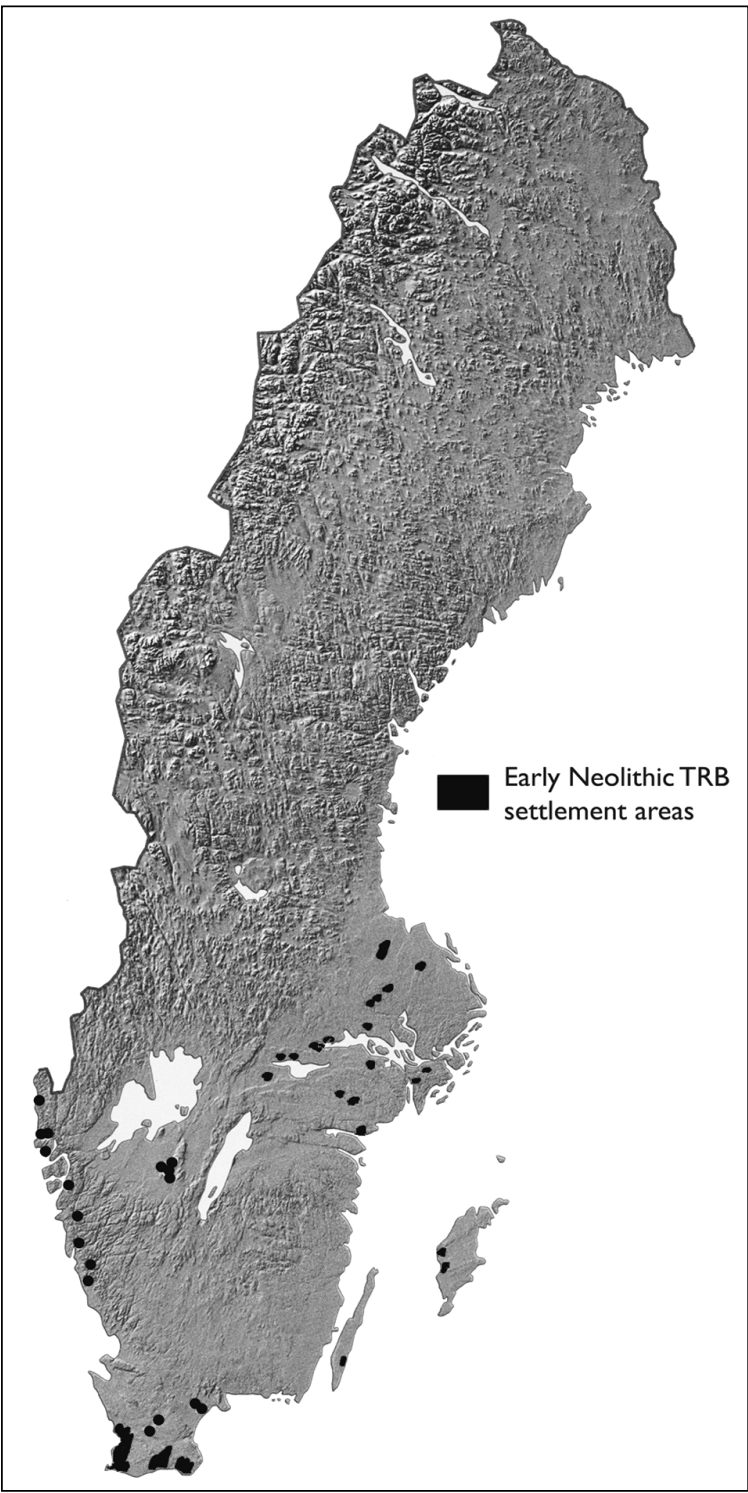

Fig. 4a. The known areas with TRB settlement in Sweden.

finds appear to the archaeologist as separated islands in the archaeological material, with large gaps between. These islands may have functioned as bases along a migratory route, something that is necessary for information about the new places to be relayed to home areas. The individuals that explore such distant new areas are dubbed scouts by David Anthony, and their activities may be identified in the archaeological material as small settlement sites with few finds. This is actually true of the early sites in the area, and at these sites we find evidence of close contact with the old homelands that is symbolically enacted in normative behaviour (in sociological terms, habitus), and in relation to lithic production and the use of raw materials. In the second phase of colonisation, we find the creation of distinctions shown by the varied use of the landscape and the

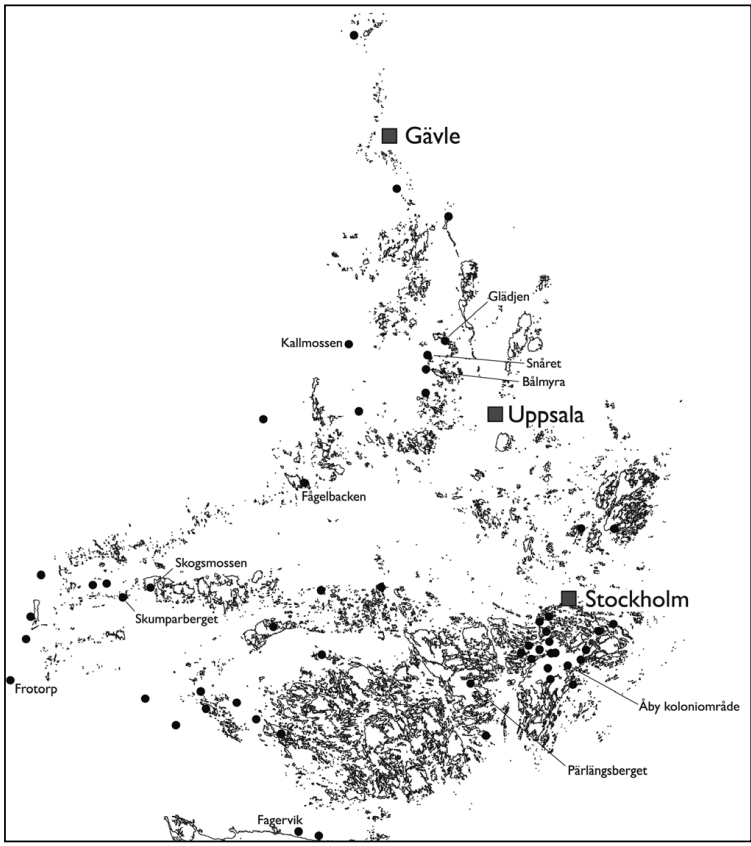

Fig. 4b. All Early Neolithic sites excavated in Eastern Central Sweden between 1935-1996. They are dated to the time span c $4000 \mathrm{cal}$ BC to c $3300 \mathrm{cal}$ $B C$. The sites are shown in relation to the shoreline c. 3900 cal BC. The concentration of sites south of Stockholm is due to recent building activities.

use of new raw materials, in some areas overtly distinct from that of the old homelands. As new identities were formed and consolidated after about 500 years, active appropriation is so far that of new land by scouts, in areas made available by the melting of the glaciers. This process can be seen, from archaeological patterning, in Northern Norway, Finland and Sweden. The social landscape thus formed by hunter-gatherers' interaction with the changing environment, created a seemingly conservative spatial structure that is visible throughout prehistory and actually later history (Fig. 6). This can be understood by turning to landscape archaeology and the concepts of landscape as memory, because when a landscape is filled with history, it structures the later cultural and social processes. As will be shown later in the contribution by Fredrik Hallgren to the project - this historically formed spatial structure represented the social environment within which neolithization took place. As local groups with their own cultural distinction were formed by budding off during deglaciation, they were still part of the same exchange networks, as shown by the spread of lithic raw materials between areas (Fig. 7). It can be assumed that these historically formed material relations also concerned non-material aspects of culture and thus had even deeper meaning in terms of cultural reproduction. 


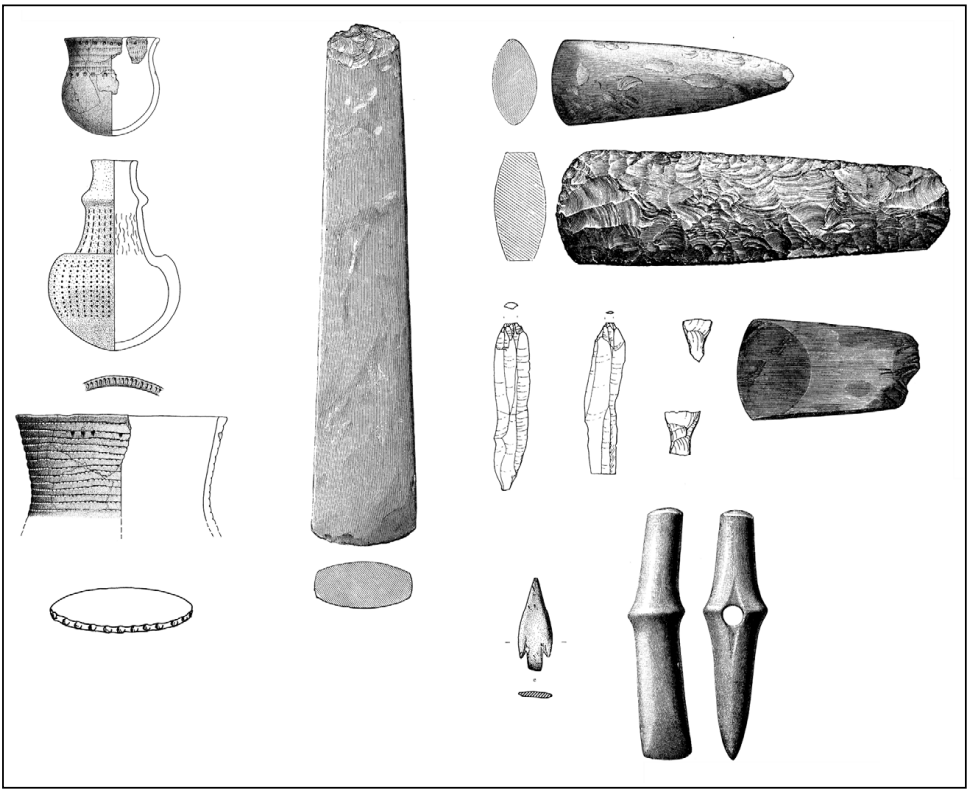

Fig. 5. Material culture of the Funnel Beaker Culture in Eastern Central Sweden. Pottery, flint- and greenstone thinbutted axes, imported flints, slate points and the typical battle axe. rial culture. The northern groups experienced a drastic paradigmatic change, at least as shown by a change in material culture. The latter process must have meant, according to a "social theory of critical situations or paradigmatic change", the formation of a new identity and thus by necessity a new version of the past.

Paradigmatic change is always painful to the people involved and always invokes a special sense of the past. The past in these situations forms the basis for establishing the new order. As a consequence of this theory of historically informed culture change, the hunter-gatherers north of the TRB border in this analysis can be shown to have appropriated a new past, a past that, according to the characteristics of their material culture (quartz

The Late Mesolithic handle-core tradition is important for an understanding of the mechanisms and extension of Neolithization in Scandinavia from the perspective of interaction networks and historical ties between groups. We find it as a signature on sites ranging from northern Germany to northern Swedish Lapland. This technology was, according to several hundred radiocarbon datings from hundreds of sites, established contemporaneously, but within variable techno-complexes such as the Lihult Culture, the Ertebölle Culture, the North Swedish Macro-blade Group etc, to be found over most parts of western Scandinavia around $6700 \mathrm{cal}$ BC (compare Fig. 8). It indicates a wide social network at the time, according to Kjel Knutsson's investigation, based not only on population densities in line with a materialistic explanatory framework, but on the history of early group formation in this area. Another important aspect of this technology is that it also vanishes contemporaneously in the archaeological material in a huge area north of the province of Skå ne (Fig. 8). When the handle core institution as we may call it, disappears around $4500 \mathrm{cal} \mathrm{BC}$, we see a change and split in symbolic communication among the Late Mesolithic groups, a split that cut the historically formed relations within these hunter-gatherer communities and partitioned the south from the north. The southern groups, later transformed into what we call the TRB culture, at this time incorporated and made use of a public symbolism related to some aspects of the south Scandinavian Ertebölle sphere, as illustrated by the active copying of mate- tools, slate implements, new type of dwellings), attached them to a northern identity. This new rela-

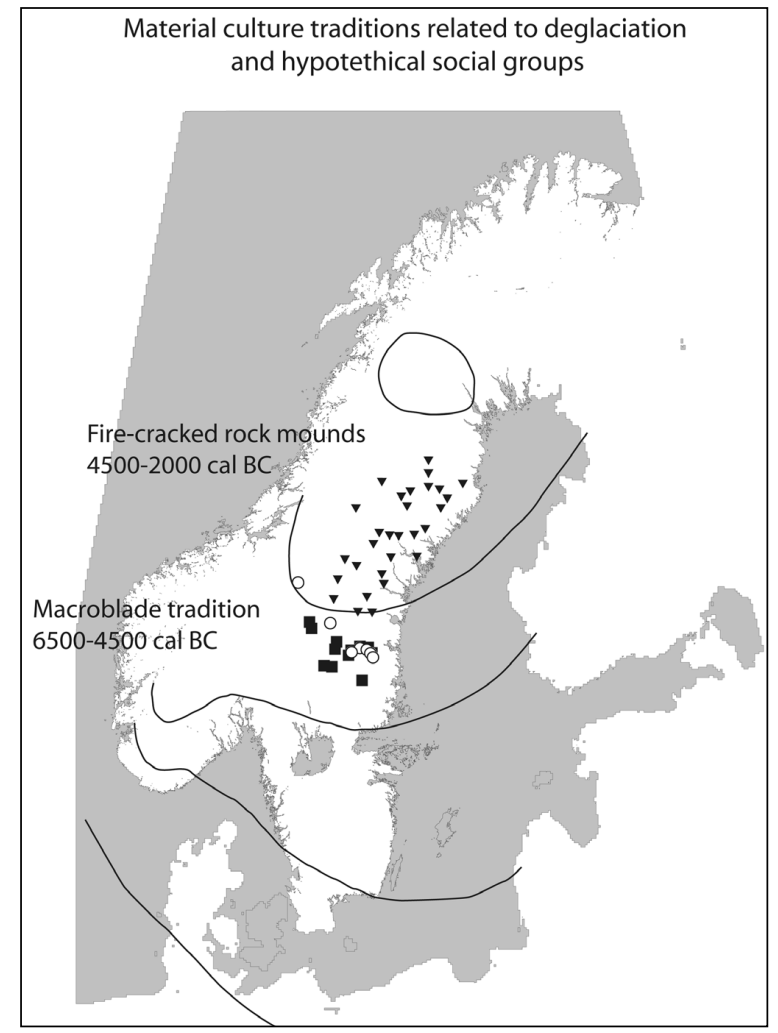

Fig. 6. The process of deglaciation, as shown by the extension of the ice sheet at intervals of 500 years. Projected onto this are archaeological "technocomplexes" indicating a tight relationship between the deglaciation process and the formation and historical reproduction of hunter-gatherer groups. 
tionship expressed as a common past, is thus materialized as a set of tools and raw materials that bears on and mimics the relics from an earlier part of this area's history (Fig. 9). The study has shown how long-lasting historical structures (the past with us) is a fundamental part in the reproduction of social formations, but also, how an active relation to a distant past (the past before us) may act as important stepping-stones for the formulation of new identities and with it a new-old past as a vehicle for them. This new distinction between north and south in central Scandinavia around $4500 \mathrm{cal} \mathrm{BC}$, formed the unintended socio-cultural substrate that set the agenda for the spatial distribution of the Neolithzation in this marginal area of northern Europe. Or as one of the PhD students of the project, Fredrik Hallgren, puts it: "the change was structured by the structure of the Late Mesolithic configurations" (Hallgren 2002).

\section{SOCIAL NETWORKS AND CULTURAL TRANSFOR- MATION}

The establishment of social groups in Scandinavia may, as proposed above by Kjel Knutsson, have been related to the speed and directionality of the deglaciation. The Late Mesolithic groups in Scandinavia that are archaeologically visible as techno-complexes (Ertebölle, Lihult, Nöstvet, The Eastern Quartz Complex etc.), thus may be said to have had historically constituted exchange connections and spatial expression, the former being shown in the down-theline distribution of exotic materials such as flint microblades from the southernmost part of Scandinavia found on sites in eastern central Sweden and Norrland (Fig. 7). The Late Mesolithic groups in southern Scandinavia in the fifth millennium cal BC, as defined by their material culture, thus may have formed a sphere of interaction that was maintained not only as a function of population density in relation to the need for social and biological reproduction, but on the basis of common historical roots. These groups may be discussed in relation to the concept of ethnicity. Ethnic distinctions can be found at different structural levels. The "cultural groups" in the area may thus, according to Fredrik Hallgren (2000), be discussed and analysed using anthropological and generalizing concepts such as band, dialect, tribe, and language family (as used by Newell et al. 1990). The local groups that formed as new land was settled during deglaciation may thus best be understood as dialect tribes in a larger community referred to as a language family. It is within the latter, larger structure that the Neolithization took

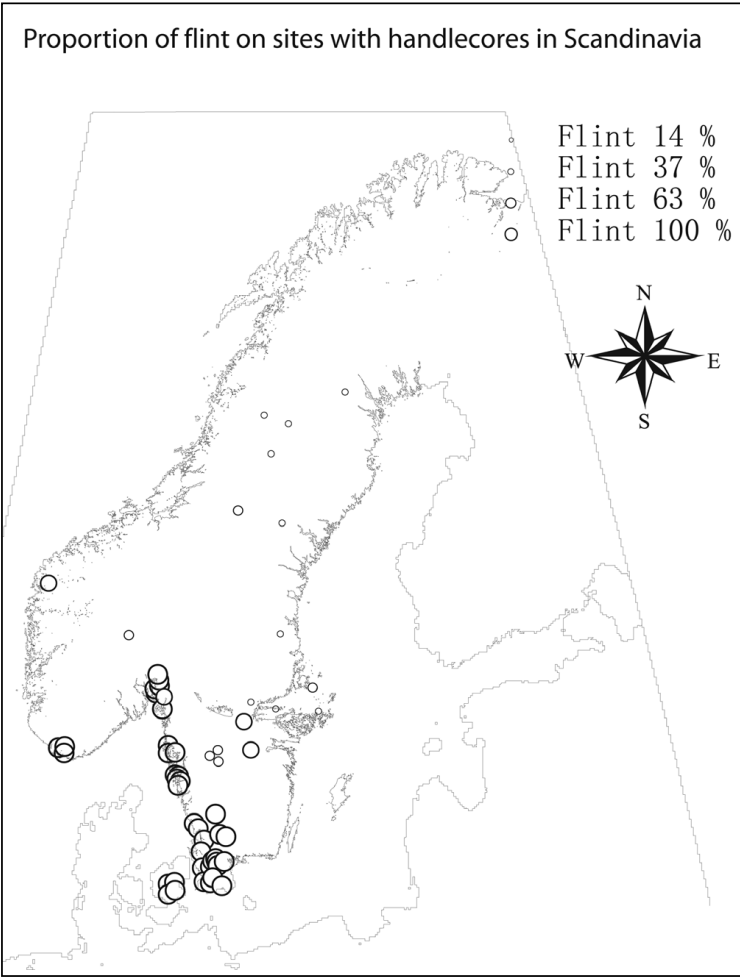

Fig. 7. The spread of exotic, south Scandinavian flint in northern Sweden during the Middle Mesolithic indicating down-the-line exchange networks. The scale of integration may be related to historical relations established as the result of the history of group formation during deglaciation.

place. It must be noted that ethnicity has no essential quality. It is dynamic, and people may change identity, ethnic groups may split or merge and above all, material culture is not a simple projection of an ethnic unit defined by its common origins or territory. Therefore this discussion is problematic in terms of what people actually thought about and how they expressed their identity in this time. The basis for this discussion is, however, the fact that spatial material patterning shows continuity over time and thus may be discussed as expressions of identity.

Around 5400-5200 cal BC, the Linear Band Pottery Culture and with it the first farming economy was established over large parts of central Europe up to northern Poland and Germany. When the spread of the Neolithic way of life, manifested in the appearance of the Funnel Beaker Culture (the TRB), advances north of this border around $3900 \mathrm{cal} \mathrm{BC}$, the change in material culture occurs according to a large body of radiometric evidence, simultaneously over the whole of southern Scandinavia up to and including central Sweden (Fig. 10). It is proposed by Hallgren that the spread should be seen as a transfor- 


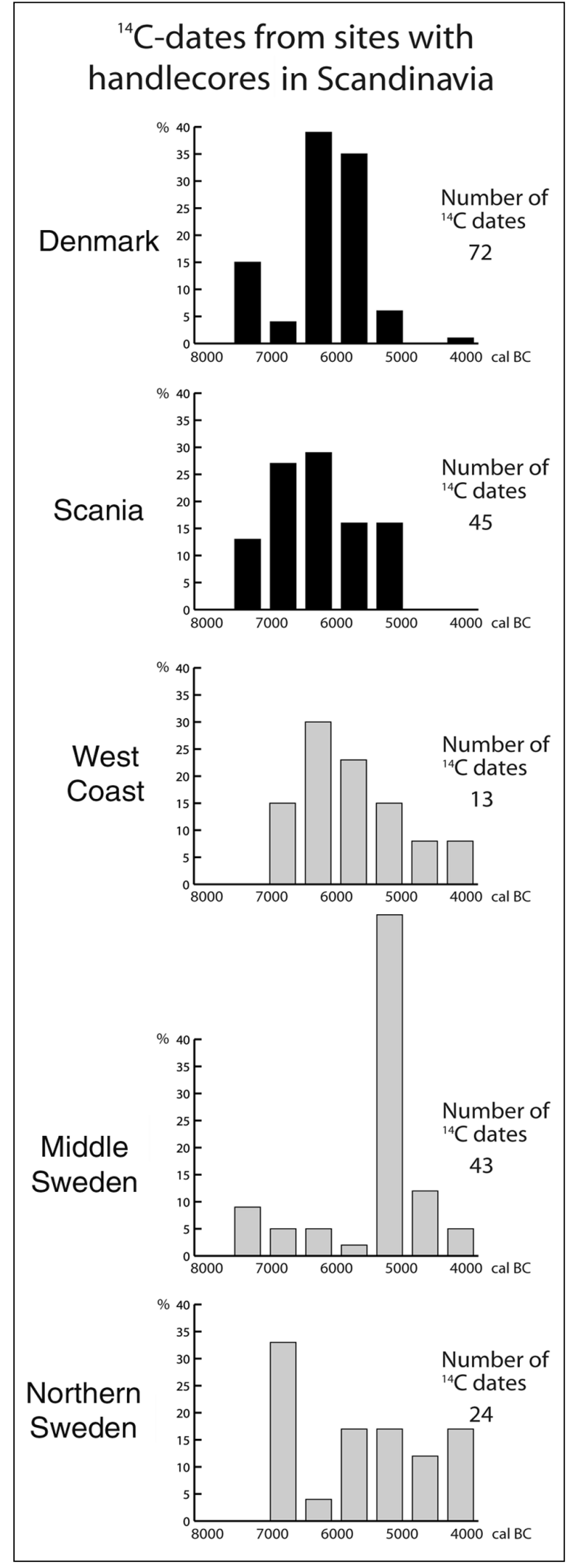

Fig. 8. ${ }^{14} \mathrm{C}$ datings from all excavated Mesolithic sites with the handle core tradition from Scandinavia. The fact that this technological tradition is established simultaneously over the vast area from northern Germany to northern Lapland, indicates established social relations and exchange networks. mation within Late Mesolithic society. The sharp geographical limits of the new phenomenon, the TRB culture, as well as continuities in material culture, speak in favour of this, since it follows and respects the age-old Mesolithic borders (compare Figs. $11 \mathrm{a}$ and $\mathrm{b}$ ). It is suggested by Hallgren that marriages between different exogamous bands within the local groups in south Scandinavia, local groups participating in the same marriage networks, was the medium for the spread of the knowledge and new way of life, since marriage is an example of contact that is most commonly arranged between persons that originate from the same dialect tribe or language group. Ceramic technology and crop growing is introduced early in the Neolithization process and it may be the moving partner in the marriage networks that brought the new knowledge. Hallgren has also suggested that the social network of the Late Mesolithic society underwent a complete change with the creation of the Funnel Beaker Culture. He argues that a new, lineage-based society was formed, perhaps with changing gender roles as a result of the transformation of the social structure. One such change might be to the post-marital rule of residence, since the ceramic technology in the Late Mesolithic was assumed to have been introduced by in-moving spouses that, according to the rule of residence, belonged to a specific gender group, had changed by the Early Neolithic since the ceramic technology now was, as will be shown below, reproduced vertically through generations in a unilinear lineage. Hallgren's analysis of TRB houses in relation to a cross-cultural sample indicates that there might have been a change from patrilocal to matrilocal rules in post-marital residence patterns. This, as a consequence, indicates that it was the female gender moving within a Mesolithic, patrilocal rule of residence that first introduced pottery and farming to eastern central Sweden. A characteristic of matrilineal, matrilocal societies in general, a social structure proposed for the TRB in eastern central Sweden, is the occurrence of special men's houses. These houses are seen as a device to bring the men together as a group as they, as in-moving spouses, find themselves as strangers in the new environment. No such houses have, however, been found, but sites show a "clearly marked, spatial structure, with spatially separated activity areas" (Hallgren 2000.16) (compare Figs. 16a and b). The importance of controlling space may be explained by the desire to separate males from females. Perhaps the spatially separated activity areas served the same purpose as the men's houses. This possible distinction between female and male genders materialized on the TRB settlement sites has 
been discussed in more detail by another member of the Coast to Coast project, Cecilia LidströmHolmberg, on the basis of an analysis of the find contexts of querns. We will return to this below.

The variation in archaeological sites of the Early Neolithic in eastern central Sweden also has some bearing on the interpretation of the social and economic organisation of the TRB culture, well in line with the proposition of a lineage based system. Aggregation sites with evidence of fishing and seal hunting are found on the coast, agricultural farmsteads with remains of cattle, sheep, goat, and cultivated plants on the sandy soils in the interior. Hallgren proposes that the interior farmsteads were part of a mobile swidden agriculture economic system and, based on the number of and the age of a series of radiocarbon dated pots from an offering fen at the Skogsmossen site, he suggests that the farmsteads were used at three periods covering at least 15 generations and that it had a succession of c. 200 years with a duration of each occupation of 25 years (Fig. 12). Several facts indicate that it was the same social unit that kept returning to the same spot. One of them is the fact that there is a strong continuity in the decoration of the pottery from the different phases. The stability in the design over some 15 generations shows, according to Hallgren, that these norms were transmitted and reproduced vertically through generations. Thus, they appear to have been bound to, and reproduced within a social unit rather than by single individuals, which points to a unilinear lineage that may have been either patri- or matrilinear. This interpretation suggests a degree of territoriality. The TRB sites in eastern central Sweden may therefore be interpreted as equal segments in a segmentary social system and as occupying a specific place within that system. As will be shown below, this non-hierarchical segmentary principle of social organisation attributed to the TRB culture in eastern central Sweden based on ceramic style analysis actually gets further support from the analysis of the production and distribution system of the thin-butted greenstone axe carried out by another member of the Coast to Coast project, Lars Sundström.

\section{A COLLECTIVE IN PERIL}

In his contribution Lars Sundström (2003) addresses two interrelated and equally fundamental questions that bear on the cultural transformation we call Neolithization: human nature and the mechanism responsible for social change. The first problem relates to how we approach the concept of equality. Have humans a natural propensity for equality or is it a culturally constructed ideology? He argues, based on a discussion of newly developed theories on this issue, that equality is a cultural construct, an ideology, and thus that it has to be continually reproduced. This notion has fundamental consequences for how we approach Neolithization since, according to him, social change is closely related to conflicts that de- 
velop between a social ideology as structure and human action (praxis). Based on a study of how people actually react to changes threatening social ideology and thus the social order, it is proposed that the archaeological signals that indicate change at the Neolithic transition (TRB material culture, burial customs etc.) actually could reflect act of defence by a hunter-gatherer social ideology based on an idea of equality. If this is true, not only are social ideologies (culture) manifested by communication through public symbolism (material culture), but social conservatism must have been an important factor in the process of Neolithization.

To understand this character of change then, the social institutions responsible for maintaining a social ideology have to be discussed. The pronounced ideology of equality proposed for Late Mesolithic society

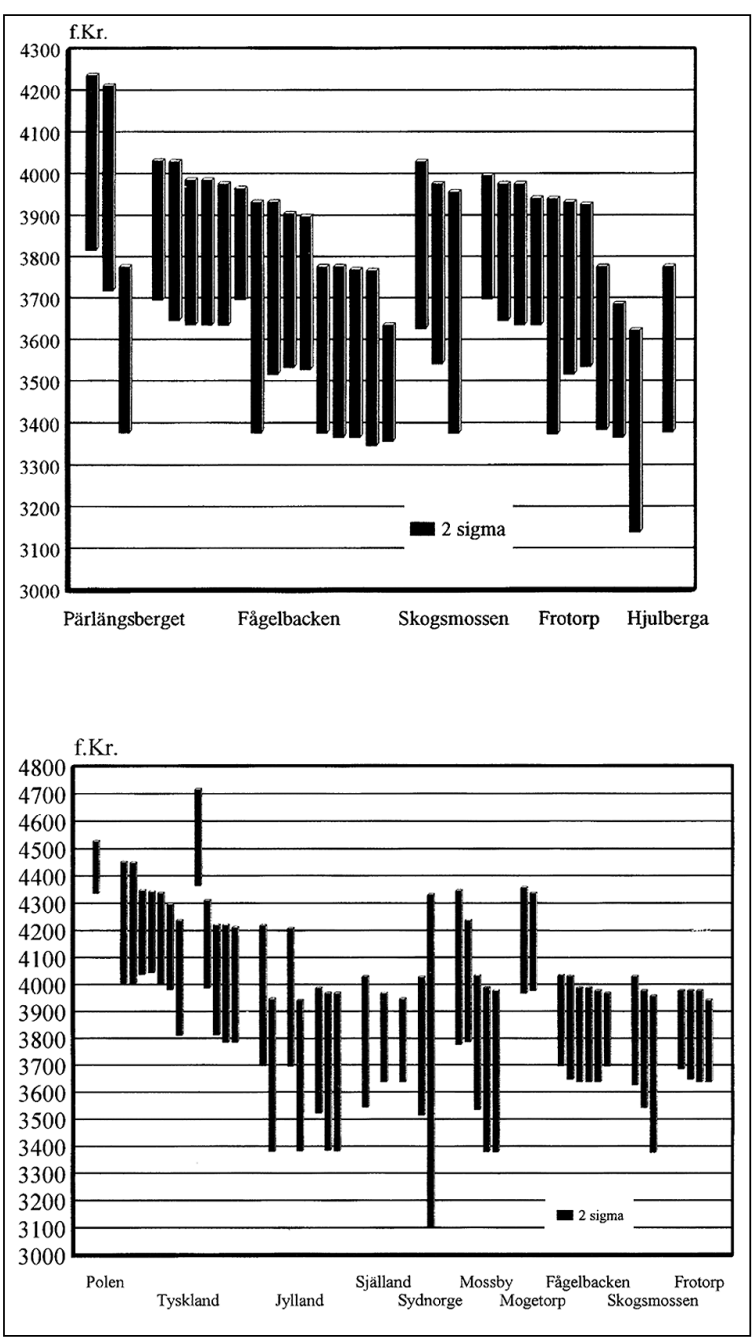

Fig. 10. Published ${ }^{14} \mathrm{C}$ dates from Funnel Beaker Culture sites in central Sweden (from Hallgren 1996). Note that the TRB tradition is established contemporaneous over the whole south Scandinavian area including Eastern Central Sweden. needed its own institutions of reproduction such as sharing, sanctions against the accumulation of property, and mobility. It was when these institutions were threatened (for example, mobility by the settled life of farming) that the ideology was made discursive and therefore possible to act upon. Based on the notion of culture as expressed in public symbolism, Lars Sundström shows that various material expressions (the treatment of human bones, decoration of pottery, polishing of axes etc.) were used to regulate and manifest the social order. The Funnel Beaker Culture must therefore not only be seen as a reflection of a new economy, but also as a material manifestation of the threatened egalitarian ideology. It was a social message, saying that in spite of the settled life and its consequences, everything would remain as it always had been.

It was stated above (F. Hallgren's contribution) that the pottery found on the TRB sites in the area indicated an "egalitarian" social organisation built on equal parts in a segmentary social system where the traditions of norms were transmitted and reproduced vertically through generations pointing to unilinear lineages in the area. Microscopic analyses of clay and temper in the pottery further strengthen this interpretation, since they show that the rawmaterials for production were unique to each farmstead. On most of these inland farmsteads, production debris from thin-butted greenstone axe production was also found. Petrography analyses of the flakes from the knapping floors indicate that the raw-material sources for this production were also unique to each settlement, strengthening the proposed social interpretation. A similar analysis of stray finds of thin-butted axes indicates that these were used and later deposited at other farmsteads than the producing ones (Fig. 13b). Lars Sundström has two possible interpretations of the production-consumption pattern. One takes into account the moving systems typical of slash and burn gardening societies and proposes that the axes followed their producers and consumers to new habitations. The other suggests sharing institutions, which have been proposed as an important source of social power in egalitarian societies, and sees the consumption pattern as a result of sharing networks in a shared territory (Fig. 13c). In times of trouble, as was discussed in the first part of this paper by Kjel Knutsson, people, and thus social groups, tend to return to a conservative retrospection and preservation of the old, to seek comfort and legitimacy from an idealised history. Apart from representing ideology in material symbolism then, the past seems to have 
also been activated in rituals in the Early Neolithic in eastern central Sweden. This is shown by the remains of rituals at coastal sites, where the past seems to have been made active by reference to ancestors. At these TRB coastal hunting stations in Eastern Central Sweden we find remains of rituals where the dead were buried and de-individualized by burning (Fig. 16c). This effort to reproduce the collective spirit was thus metaphorically tied to hunting. In Sundström's argument the TRB ancestors were thus still hunters and gatherers in the early Neolithic, representing and legitimizing an idealized social structure. As shown in many anthropological analyses of segmentary cultural systems, they are normally quite short-lived. The built-in conflict between the social ideology of equality and the real world of land ownership and a settled life makes the members of the society insecure and the entire soci-

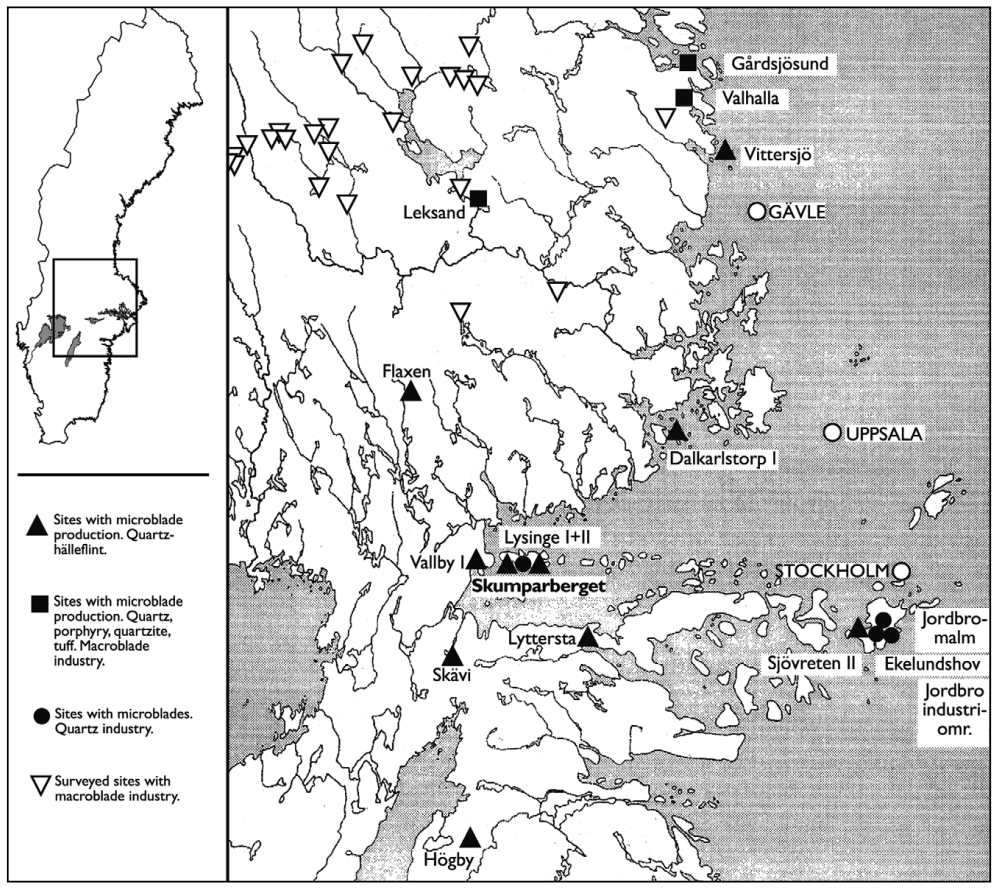

Fig. 11A. The distribution of Late and Middle Mesolithic sites (the Handle core tradition) in Eastern Central Sweden and southern Norrland. Two techno-complexes are found here. A northern group (open triangles with a distinct macro-blade industry and a southern group characterized by a knapped quartz industry. ety moves towards a crisis (this may take centuries!). He interprets the cultural patterns of the following Middle Neolithic period as two different reactions (Fig. 16) to this crisis, an in the end unbearable situation forcing the groups to change their culture and social structure.

In the southern part of the TRB area there seems to have been a strengthening of social control. The construction of collective central sites of the Sarup type in the Megalithic TRB phase is thus seen as a manifestation of ritual practices aiming to reinforce and preserve the collective, the idea of egalitarian relations. In the northern part of the area, the tension within the segmentary TRB society takes another form. Here, the past acts as a stepping stone for change. The idealized hunter-gatherer lifestyle presented in the reproductive myths and played out during ancestral cults at the coastal sites is actually returned to. The transformation of the farming TRB culture to the hunter-gatherer Pitted Ware Culture is thus explained by Sundström as a way of solving the crisis by reintroducing a lifestyle that made the institutions that reproduced the egalitarian mode of life possible to uphold.

As we move into the end of the Middle Neolithic the societal conflict in the southern TRB is finally solved by the construction of a new past. As will be shown by the work of Helena Knutsson below, the cultural heroes of the bearing myths change: no longer are they hunter-gatherers, but landowning farmers. The idealized farmer of the new ideology is materialized by the ritual paraphernalia attached to those interred in BAC graves, which are installations for reproducing individuals within a new social order.

\section{QUARTZ, QUERNS AND SOCIAL IDENTITY}

We have so far argued that the cultural change around $4000 \mathrm{cal} \mathrm{BC}$ had long-lasting historical roots and thus that the change was structured by Late Mesolithic configurations. The change is further seen as a manifestation and defence of the old hunter-gatherer egalitarian ideology. TRB material symbolism expressed equality. Since this was a materialization and thus visualization of the previously embedded ideology of hunter-gatherers, it became vulnerable to critique and thus to change. We have also discussed the importance of the constructed past in reproducing society and that the TRB past still was a past of hunter-gatherers metaphorically manifested during ancestral cults at hunting stations. The reproduction of society is, however, not only expressed in ritual contexts. The routines of everyday behaviour 


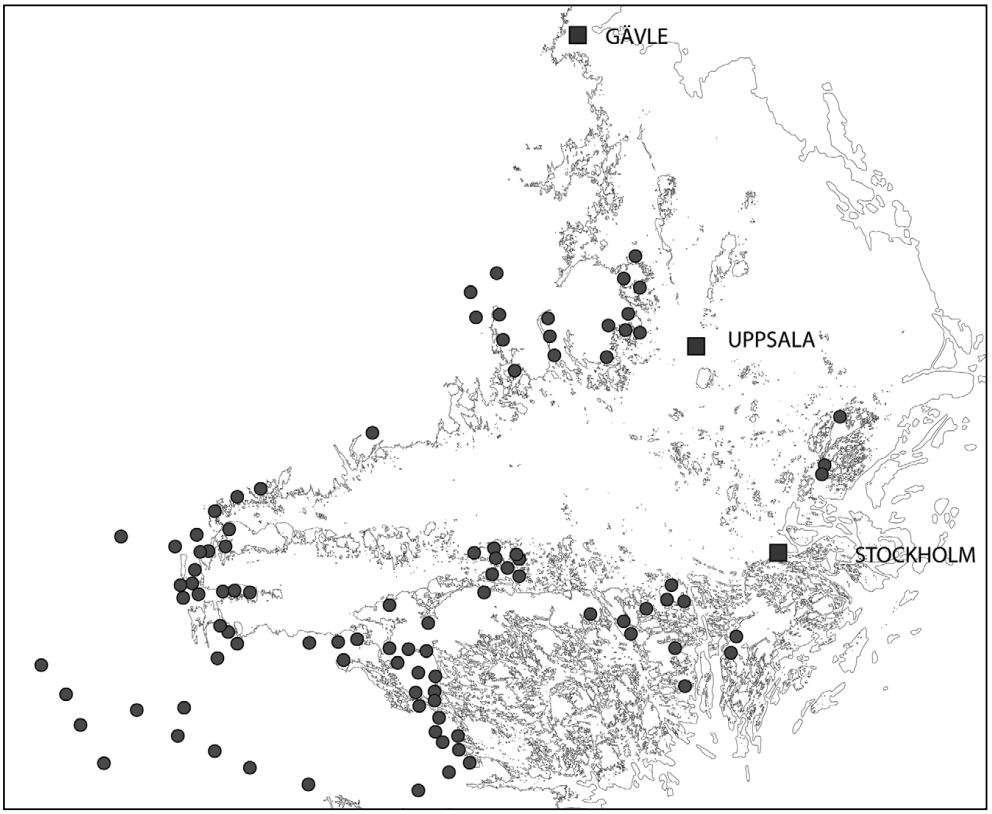

Fig. 11B. The distribution of multifaceted shaft hole axes in Eastern central Sweden represents the settled areas of the Funnel beaker Culture between 3900-3300 cal BC. Note the continuity in the North-South distinction between time periods where the TRB is formed only in the southern hunter gatherer group (compare with Fig. 11A).

comprise another arena where central categories are played out. In times of cultural change these cultural codes are re-evaluated and changed. Different domestic technologies are part of everyday behaviour and thus cultural codes are enacted as they are implemented, for example, on settlement sites. The way we understand and use the concept of technology is thus critical to how we deal with questions of prehistoric cultural transformations such as, for example, the process of Neolithization. Taking an engendered view of technology as a starting point, Christina Lindgren and Cecilia Lidström-Holmberg, have analysed changes in quartz tool technology and the production and use of querns/grinders during the Mesolithic-Neolithic transition process.

According to an analysis of compiled, radiocarbon dated sites, there seems to be a change in quartz technology in eastern central Sweden around 4500 cal BC (Lindgren et al. 1997). This change occurs simultaneously to the shift in symbolic communication and possibly ethnic distinction between north and south that was discussed by Kjel Knutsson earlier in the paper. Using a newly developed theory of quartz fracture patterns, the social dimensions of technology and Giddens theory of structuration, Christina Lindgren describes a reproduction of cultural codes and social organization, where the relationship between technology and praxis communica- tes identity within settlements. Referring to the general ideas of a "preNeolithic" change discussed by Knutsson, Lindgren uses the two identified technologies (platform and bipolar-on-anvil methods, compare Fig. 3) to describe a process of social change. Shifts in size and variability of Mesolithic sites in the area seem to harmonize in time with this change in technology. Before 4500 cal BC the sites are characterized by great differentiation of habitation area sizes, the tasks performed in them, inner site features and artefact production technology. In the three former aspects, the younger sites seem more homogenous. All over the transition period, the sites are situated on the beaches of the outer archipelago islands (Figs. 2 and 15). A preliminary activity area analysis using the quartz fracture pattern theory, of excavated Mesolithic sites dating both before and after $4500 \mathrm{cal} \mathrm{BC}$, does not, however, seem to indicate any change in symbolic communication on site level. This may indicate that the change in quartz technology related to other aspects of the TRB society than social roles or that it was not part of the social distinction. As we will see, other aspects of material culture seem to relate to a need for social distinction in the TRB.

The TRB inland sites in eastern central Sweden interpreted as farmsteads with evidence of domesticates such as cereals and cattle showed, as discussed earlier by Hallgren, "clearly marked, spatial structures, with separated activity areas". A tentative explanation presented by Hallgren stated that this need to control space may have been the result of a desire to separate males from females. This possible distinction between genders materialized on the TRB settlement sites may, accordingly, relate to social changes in the local Mesolithic community resulting from the new situation impinged on society by a new way of life. This change started probably with a shift in symbolic communication and social roles related to large-scale changes in social relations and ethnic distinctions at this time, as proposed earlier in the paper. Studying the social structure of the TRB society by means of a contextual analysis of grinding tools from the area, Cecilia Lidström-Holmberg (1998 in press), in accordance with her view on technology, wants to challenge the traditional 
paradigmatic discourse on querns, where it was assumed that they had no social intentional meaning beyond the functional. The low archaeological value, she says, may have been due to negative associations, "a monotonous and unqualified female task", related to a set of historical values that are brought into play in interpretations. Instead, Lidström-Holmberg wants to explore prehistoric value systems by means of critical gender theory. The grinding tools, she states, can be interpreted as an active part of Neolithic social and ritual life in eastern central Sweden (LidströmHolmberg 1998.124-129). Grinding tools are, together with hearths, cooking pots and other food processing implements, the only stone tools directly associated with female activities, from tool manufacturing to their maintenance. If an economic and social organisation of gender relations structured the Neolithic way of life, it may also be observable in the daily material culture associated with grinding tools and food processing techniques. As was mentioned above, the Early Neolithic inland farmsteads were strictly structured and the principles for this may be interpreted as having been based on gender categories, as the activity area analysis shows separate areas for axe production, and areas with grinding equipment like querns and other food processing remains (Figs. 16a and b) (Lidström-Holmberg 1998.128).

The Mesolithic querns are usually smaller and less standardised in form than the Neolithic ones in eastern central Sweden. It is not until the MesolithicNeolithic transition that large, actively designed grinding tools appear in the archaeological record in the area. A saddle-shaped grinding slab is accompanied by a two-handed, loaf shaped handstone, both parts carefully designed by knapping, pecking and grinding (Fig.17a). The production probably required considerable technological knowledge and thus, because artefacts are produced and used in a context of interaction, the technology must be seen as part of social production. The morphological changes in grinding tool design that appear in the Mesolithic-Neolithic transition are linked by Lidström-Holmberg (1998.132) to dynamic changes within these societies. Shared ideas of grinding tools as social and ritu- al metaphors are proposed to be included within the conceptual domestication of the Neolithic communities. It is thus of importance to see that "symbolism is active in all parts of society, including daily life", a statement that brings us from the querns to the context in which they functioned, the settlement. Here the evaluation of the archaeological context is crucial as a source for the definition of the context of communal experience, since the querns in this study are seen as representations of internal experiences of culturally defined values and concepts, including gender distinctions.

Drawing on, albeit meagre, the ethnographic experience of women's everyday activities, it seems as if grinding tools cross-culturally were used, produced and owned by women. Although womanhood is a cultural interpretation of sex, grinding tools can thus in ethnographic cases at least be shown to express human relationships, i.e. ideas of marriage and social and economic interdependence and thus played a part as important social signifiers in initiation rites. During the rite, the initiates were instructed in the use of the objects, as well as in social and moral life and the role of adult womanhood. The friction between the grinding slab and the hand-stone meta- 


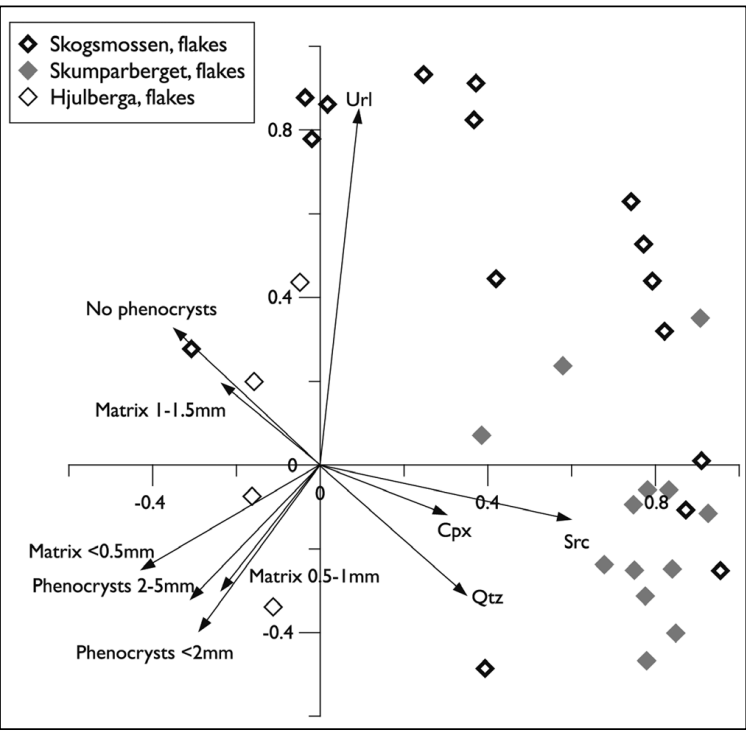

Fig. 13A. Correspondence analysis of the lithology of flakes from porphyry axe production found at three TRB farmsteads in Eastern central Sweden. Note that the lithology differs between sites but is similar within sites indicating local raw material quarries. This indicates self sufficient local groups in a segmentary social structure.

phorically came to represent the ideal relationship between man and woman. But the relationship between the handstone and the grinding slab could, as shown by other ethnographic examples, also express the relationship between age sets, for example, mother and child. A case in point in eastern central Sweden concerning the latter suggestion is two child burials at the Östra Vrå TRB site, where the charred bones from the buried children were covered by an astonishingly large number (80) of saddle shaped querns. The deposited querns where mainly grinding slabs, representing the "mother" in the mother/child quern metaphor (Fig. 17b).

Similarities in artefact remains from communities belonging to LBK and the TRB in Scandinavia have been noted for a long time. It is thus interesting to note the similarities in tool design of LBK grinding tools and the saddle-shaped grinding tools found in eastern central Sweden. The quern and its design may, as indicated by the ethnographic examples and the graves discussed, have been important in the ritual reproduction of the TRB social structure. The find contexts of querns at different sites in eastern central Sweden studied by

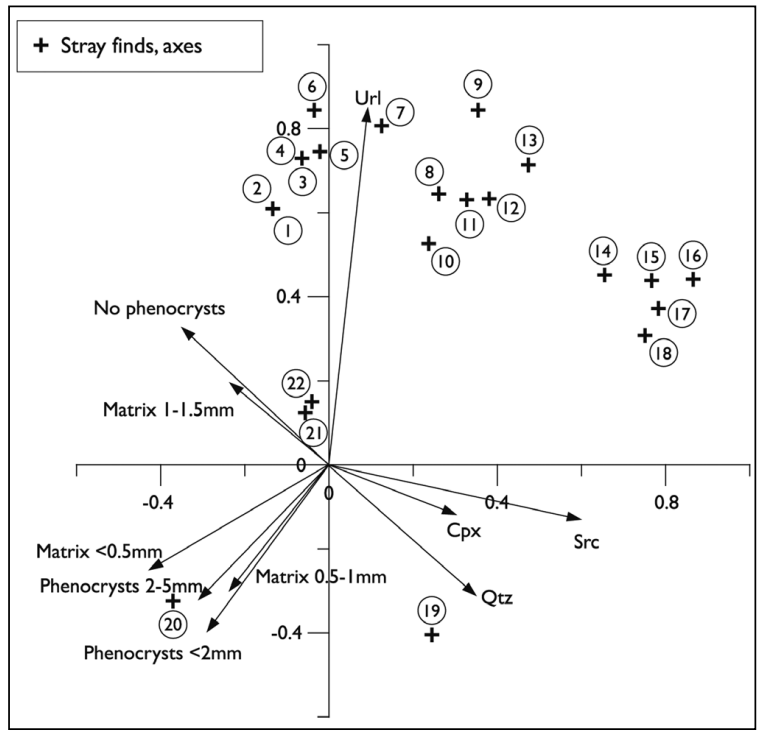

Fig. 13B. Correspondence analysis of the lithology of stray-found porphyry thin-butted axes from assumed farmsteads in Eastern central Sweden. The axes forms groups of similar lithology indicating that they have been produced at a few farmsteads (from Sundström 2003).

Cecilia Lidström-Holmberg actually point in this direction. They have been found, as already mentioned, as sacrificial offerings in graves, and as structured organization of space on farmsteads and finally, as votive offerings in wetlands.

The Early Neolithic is in general known for its many finds of pots, axes etc. in wetlands, indicating a votive offering practice. The whole of Early Neolithic chronology in Denmark is based on typology and ra-

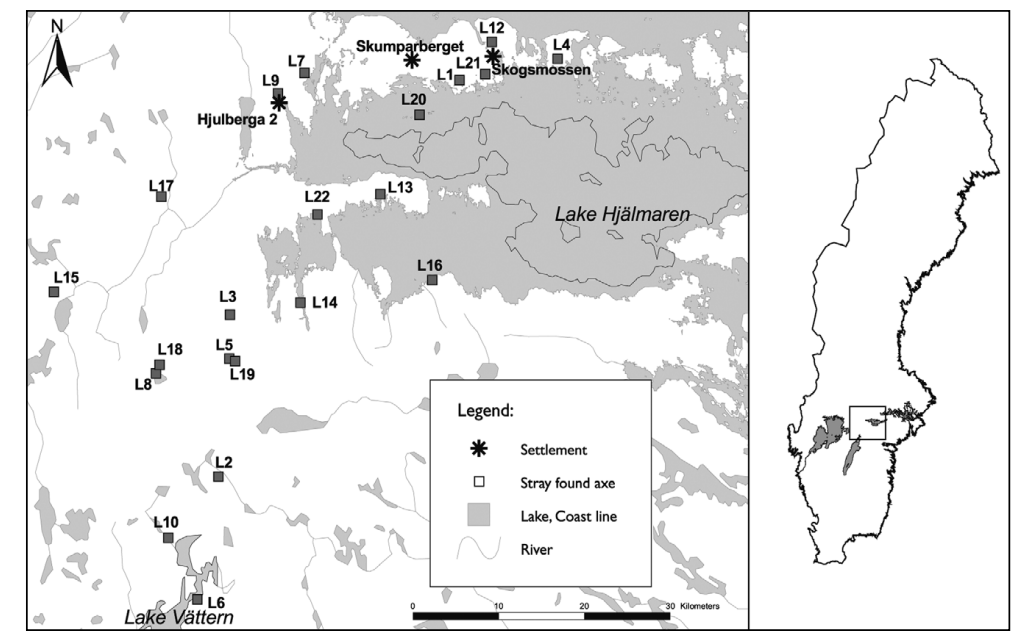

Fig. 13C. Dissemination of the stray-found axes analysed in Figure 13B. Axes from different lithological groups are found throughout the TRB landscape in Eastern central Sweden indicating a network of exchange relations or illustrates the movement of segments in the social structure within the landscape (from Sundström 2003). 
diocarbon datings of funnel-beakers found in moors. These pots are interpreted as belonging to offerings close to TRB farmsteads. On the farmstead at Skogsmossen in eastern central Sweden, a small fen, interpreted as a votive offering fen, has actually been excavated. Here, finds of pots and axes were made, together with remarkable elongated quern handstones of micaeous schist. The latter were deposited in a straight line in an east-west orientation across the southern part of the fen (Fig. 16b). The saddle shaped grinding slabs, on the contrary, are deposited in a north-south line along the fen. According to Lidström-Holmberg, then (comparing the settlement layout and the organisation of votive offerings in the fen): "The pattern of deposition in the fen may be interpreted as a reflection of the gendered living space in general." The way people structured their living space through gender ideologies seems to have set part of the agenda for both daily life (the settlement) and ritual action (the fen). The definition of symbolism as active in all parts of society, including daily life, seems to be particularly "true" at the gendered Skogsmossen site (Lidström-Holmberg in press).

Changes within the structure of households during Neolithization, as it seems, can be discussed in terms of negotiations of gender roles and gender norms within the Early Neolithic communities. Querns, food and food processing are thus seen as important gendered strategies for social action and negotiations, both within households as well as in the wider community. Cecilia Lidström-Holmberg suggests, after her preliminary investigation of the TRB quern material in eastern central Sweden, based on her critical reading of gender theory, that progress, transformation and technological advance, is indeed a gendered enterprise. Querns are socio-technological objects involved in domestic action, both manifesting and negotiating gender principles as shown by the distinctions in both the settlement sphere and the fen (Lidström-Holmberg in press). As a consequence of this "interpretation", the assumed perception of households as unchanging and known socio-economic domestic entities obviously needs to be further deconstructed before we can go beyond simple dichotomies.

The structure of the TRB social organisation, here formulated as binary oppositions, thus makes too easy a blueprint of present-day gender relations. Whatever the case may be, no doubt the querns and their contexts of deposition in eastern central Sweden during Early Neolithic, indicates a cultural need

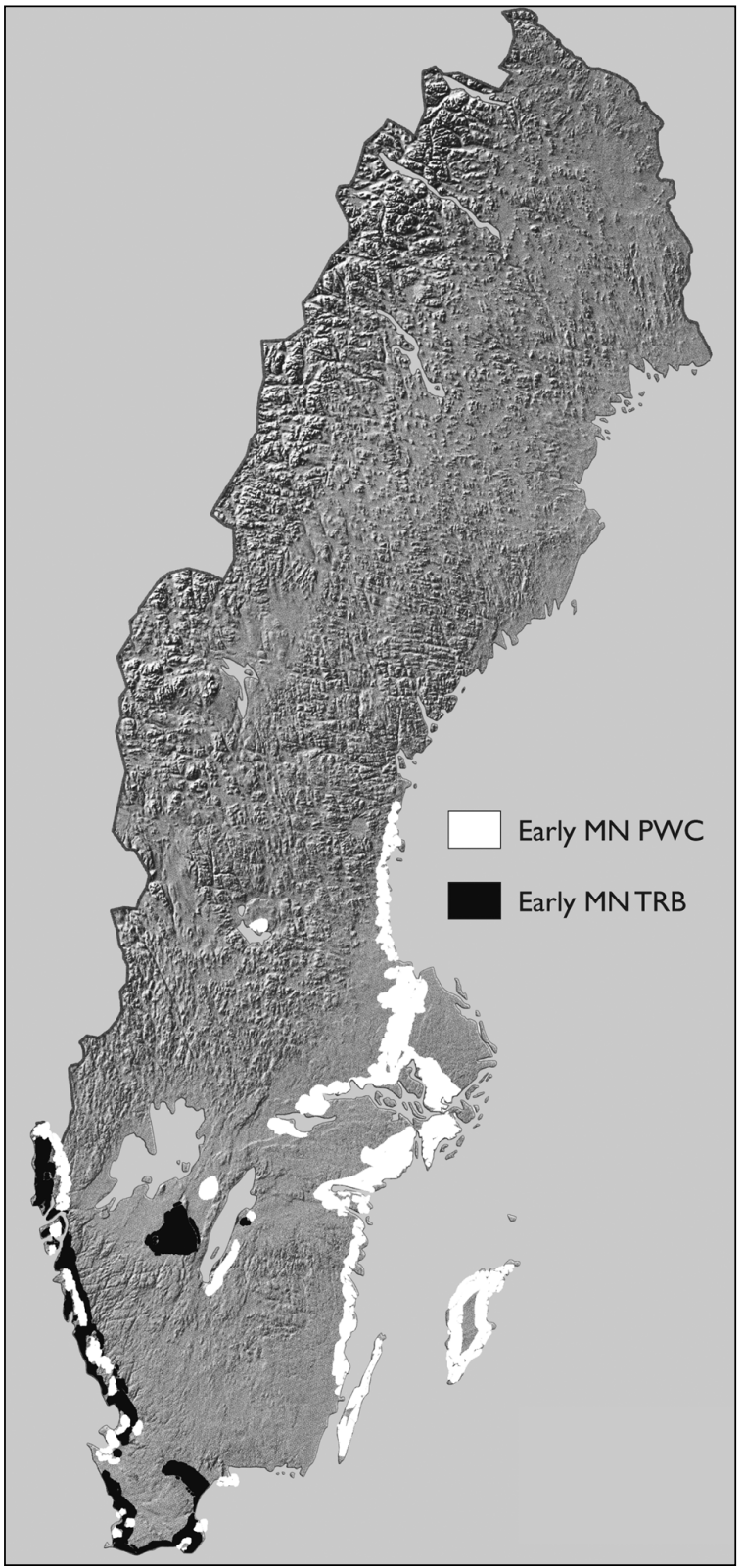

Fig. 14. The distribution of the Middle Neolithic "cultural groups in southern Sweden. Both The Pitted Ware Cultureand the Megalithic TRB are formed on the same Early Neolithic cultural substrate. The $P W C$ returned to and lived the egalitarian life of the ancestral stories, the megalithic TRB indicates a strengthened ritual control over the egalitarian social ideology (from Burenhult 1999 and Sjögren 2003).

of distinction in the TRB, a distinction that so far, according to Lindgren's study discussed briefly above, have not been found in earlier contexts in the area. The importance of a female/male separation in matrilineal, matrilocal societies has been proposed for the TRB in eastern central Sweden by Fredrik Hallgren. The references to male-female relations and fertility as metaphorically materialized in querns may thus be part of a fertility cult reproducing a do- 
mestic unit typical at the inland farmsteads. The east-west/north-south distinction of grinding slabs and hand-stones in the Skogsmossen fen calls for an interpretation of the querns as representations reproducing male/female relations, and in a wider meaning, a cosmology formulated around an idea of the "canopy of heaven". This interpretation concerns only inland settlement life. At the same time, in the coastal settlements, as proposed by Lars Sundström earlier in the paper, the same groups struggle to keep their old rituals, concentrating on the re-creation of an ancestral past, returning to the idea of a hunting, gathering and mobile life style (Fig. 16. c). This dualistic settlement structure and its social connotations no doubt by and by created a crisis in the minds of the Neolithic "eastern central Swedes". As Sundström puts it, this problem found two different solutions in the TRB region as a whole. Some groups, after some generations, changed the idea of their ancestors to make it commensurate with daily life as farmers, while others went back to the mobile hunting style of life, commensurate with the world view presented in the common rituals at the coastal settlements. The idea of "the farmer" and some of its associated material metaphors are important here and they have been dealt with by Helena Knutsson in her part of the project.

\section{BLADES FOR THE ANCESTORS}

In the foregoing we have shown that material culture must have been important in social communication in Mesolithic and Neolithic societies. In periods of change it also functioned metaphorically as a vehicle for the construction and manifestation of a new world view and thus, by necessity, a new past. If much of the TRB material culture was related to the communication of an idealized idea of equality with reference to a pantheon of hunter-gatherer ancestors, the flint blade or the harvesting sickle may be seen as a metaphorical materialization of "the farmer". Found in late Middle Neolithic graves, it may represent one important aspect of the paraphernalia, the neccesary gear, of an ancestor commensurate with the real life of TRB farmers. As such, they were actors in the reproduction of Late Neolithic society. Blades, unlike polished axes and pots, are common artefacts in Scandinavian archaeological contexts throughout the Stone Age and long into the Bronze Age. They are found in settlements, graves, and depots. In some cases their production sites have been found, usually in settlement remains. In several periods of the Stone and Bronze Age their

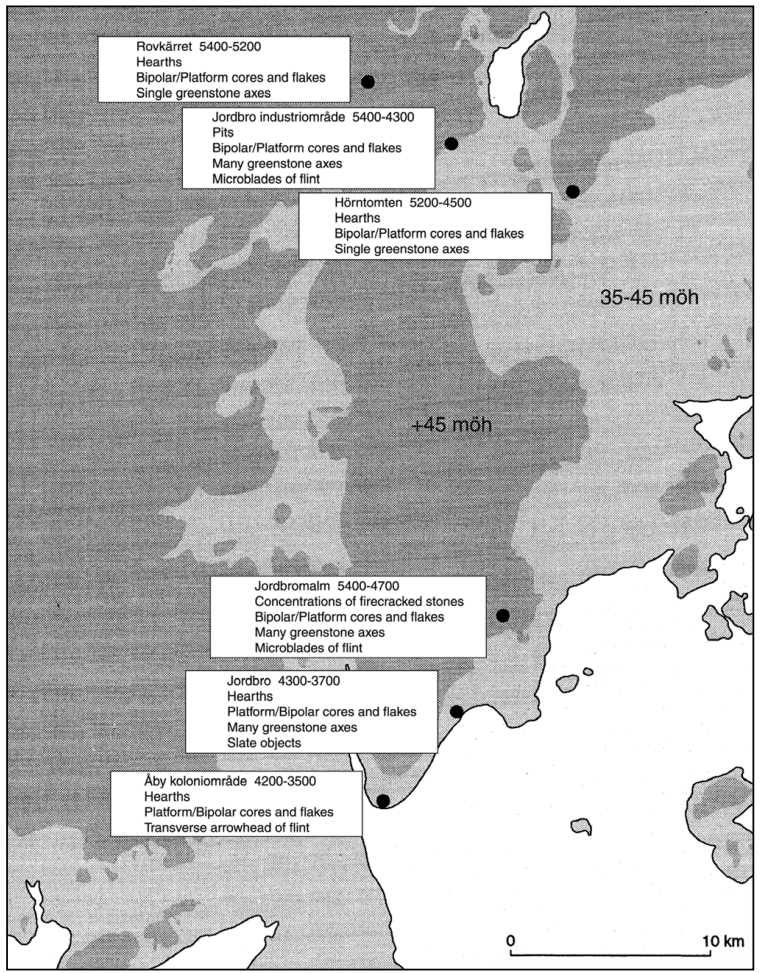

Fig. 15. Map of one micro-region in Eastern Central Sweden during the Late Mesolithic showing the variation in settlement types.

production seems to have been standardised and plentiful. So, how can we possibly understand their role in the transition to agriculture?

Helena Knutsson has chosen to look at three aspects of artefacts: the technology of production, traces of use, and contexts of deposition. Taken together, they inform us about cultural processes in the transition to farming and, as we shall see, in a way that seems logical to the idea of cultural reproduction in the Neolithic as proposed by Lars Sundström above that is, the need to create new pasts and ancestors to accommodate the new life of "the farmer". The production of blades in Scandinavia had already begun in the Late Palaeolithic. During the Mesolithic, production was more and more sophisticated, the size of blades diminished, the regularity of their shapes increased. Then, in the Late Mesolithic, the blades again grew in size, and regularity appears to have been more important then ever. During the socalled Kongemose culture, partly contemporary with the first farming groups producing linear band pottery in northern Europe, there are production sites in southern Scandinavia with thousands of blades. We also find depots with neatly packed blades (produced from one or two cores, still packed tightly together, as if they had been kept in a bag) (Fig. 18). At the end of the Mesolithic, the production of blades 


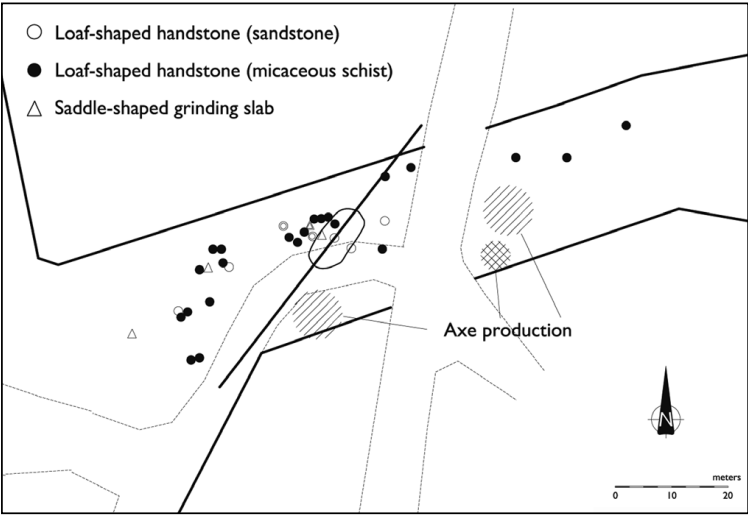

Fig. 16A. Map of the Skumparberget Early Neolithic TRB inland farmstead. Note the spatial distinction around the house of activities related to axe production and food preparation.

seems to follow other needs than hitherto. Much rougher forms were produced, regularity seems no longer important, but they are still produced in great numbers. Also, at Neolithic TRB sites in Scandinavia we find blades, but they are more regular than the Mesolithic examples, and above all, fewer. Moreover, their deposition sites changed. At the end of the Mesolithic they were placed in graves, and left in great numbers in settlements together with production debris. In the oldest TRB they are still found in the same settings, but when we look at the remains of the Middle Neolithic, deposition habits have changed considerably. The blades, often only slightly modified, increase in numbers in burials, and their context of production disappear. The same tendency can be discerned both in Middle Neolithic TRB megalithic graves and in the central and north European Corded Ware Culture mound graves. This specialised production, seemingly for ritual purposes, can be understood, as is shown by Helena Knutsson, in relation to the construction of a "Neolithic way of life".

The important thing about the change in blade production is not only the change in the deposition context of the TRB blades, but the fact that we now see two different blade technologies and two social contexts of production and use emerging from the archaeological record (see Figs. 20a and b), one related to the southern TRB farming communities, another related to the former northern TRB area with PWC hunters and gatherers. The former are, as already mentioned, found only as gifts for the dead in TRB and later on in late Middle Neolithic BAC grave contexts. They are either unused, or used as sickles for the harvesting of grain. The latter blade technology is found as both tools and waste from produc-

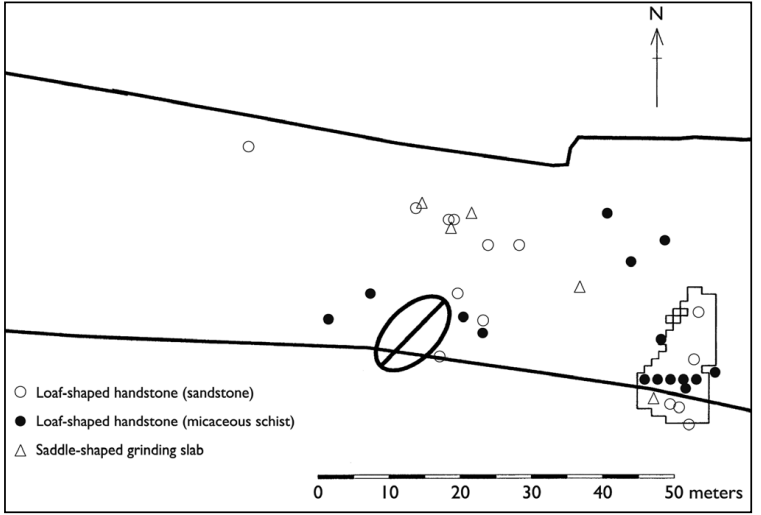

Fig. 16B. The Skogsmossen TRB inland farmstead. Note the grinding slabs and handstones in the offering fen.

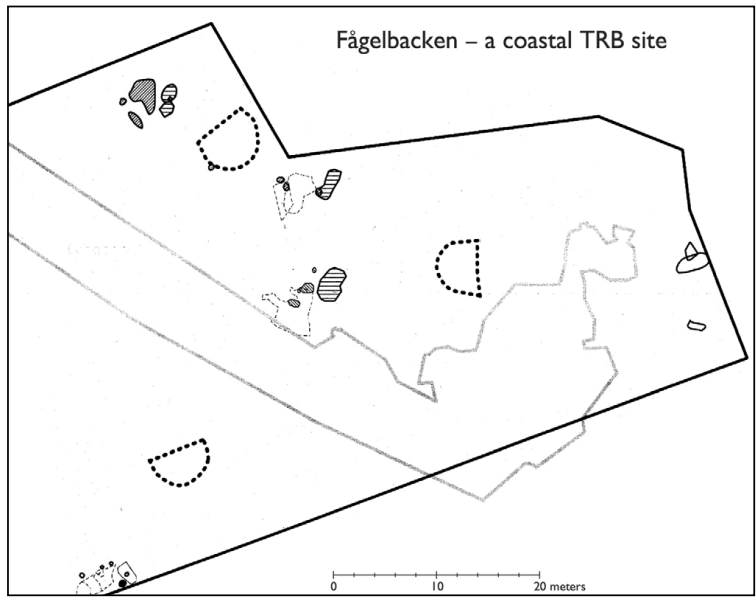

Fig. 16C. The Fågelbacken coastal TRB hunting station with pits with human burials, huts and hearths (from Lidström Holmberg 1998 and Hallgren 1997).

tion on Pitted Ware Culture settlement sites. Here, the use profile is varied, indicating domestic use in non-ritual settings.

A quick look at the continental traditions of blade production tells us a slightly different story. Blades were produced during Upper Paleolithic times, and they remained in the settlements, deposited as waste from production or after use. The Mesolithic is a troublesome concept in continental Europe, but still the materials defined as Mesolithic do not contain blades at all, or the blades found in them are made with no specialised needs in sight. With the arrival of domesticated species to Europe, the blades systematically produced and used as sickles or rather harvesting tools pop up in the settlements. This is especially documented at the Early Neolithic sites of south-eastern Europe (Perlès 1992; Demoule and Perlès 1993; Pérles and Vitelli 1999). The origin of their technology of production has been traced to the Middle East or Near East, where sources of at 


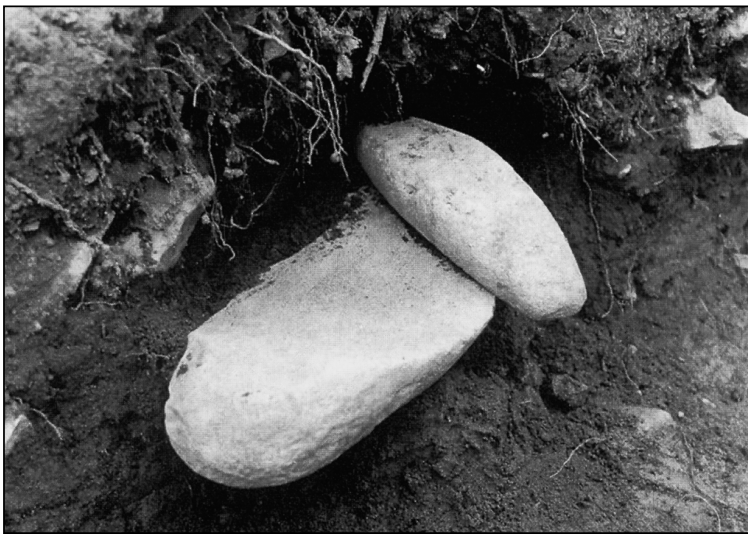

Fig. 17A. A grinding slab and handstone found in situ on at Neolithic site in Eastern central Sweden.

first obsidian and later flint were systematically exploited from the beginning of the Early Neolithic. (Özdogan 1999; Kozłowski 1999). All this exploitation and blade production began long before pottery seems to have been accepted as an important part of Near and Middle Eastern Neolithic culture. In this sense we can state that blades constituted a much more original and important part of agricultural techniques than pots and polished stone tools.

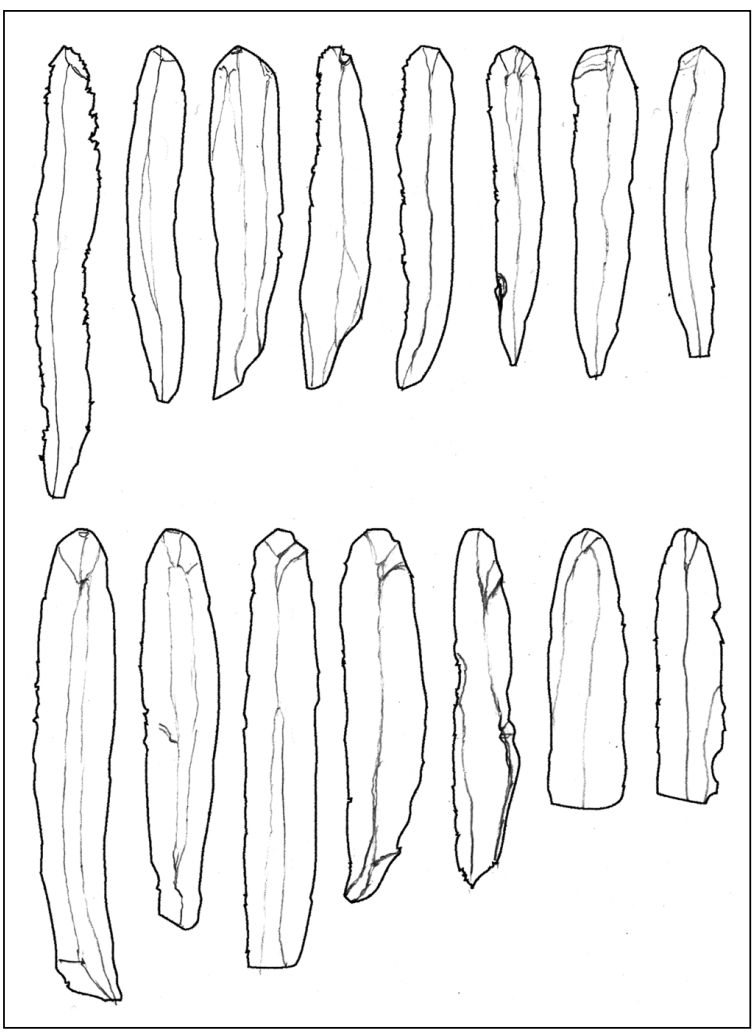

Fig. 18. A deposited package of Late Mesolithic blades from the so-called Kongemose technocomplex. This might indicate a "specialized" production of large prismatic blades already in the Mesolithic in the south Scandinavian region (after Salomonsson 1955.Fig1).

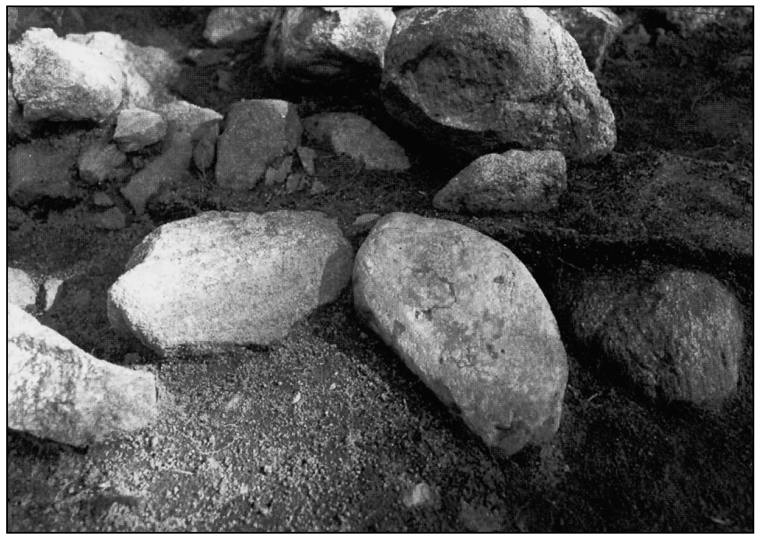

Fig. 17B. Childrens graves? from Östra Vrå in Eastern Central Sweden. The grave pit with charred bones from children where filled with grinding slabs and burnt cereals (after Welinder 1999.Fig. 162, Fig. 213).

As presented in an earlier article (Knutsson 1999), it seems reasonable to understand the suddenly increasing exploitation of several of the stone quarries in southern and central, and later even northern Europe, as a consequence of an increased need for raw materials among other things, especially for blade production. This, according to Knutsson's earlier study, probably promoted the establishment of new types of large-scale networks through Europe in Early Neolithic, which also involved hunting and gathering groups and compelled a change of life style throughout the continent (Knutsson 2002). The need for raw materials was, as even today, a crucial aspect of the lifestyle of growing agricultural societies with growing hierarchical structures. The practical reasons were, perhaps, an increasing number of people, a lack of salt to keep livestock alive, and new technologies of everyday life. Other reasons were probably the needs of elites to form groups marked by special material symbols, and maintain their superiority over other groups with the help of these symbols. The development in production and use of pottery is a good example of such a divergence in thinking (Fig. 19). Practical reasons perhaps dominate when pottery is discovered and made as a "domestic" tool, but this doesn't happen within the agricultural societies. Later, when the idea of pottery is accepted by such groups, a development starts towards a refinement of techniques for the display of the finished objects, which turns them into beautiful and not especially practical things. This idea is supported by the latest dating results of early pottery in eastern Asia (Russia and China), where the radiocarbon datings clearly show that the development of pottery has to be ascribed to the mobile hunting and gathering groups in this 
area (Kuzmin 2002; Chi 2002). The early systematic use of pottery is a part of the Asiatic hunting and gathering life style, and its spread to agricultural communities only happens long after these communities changed their own life styles. After the adoption of new life styles we can trace a divergence in production styles of pottery along hunting-gathering lines (big pots, with pointed bases and a relatively "quick" type of decoration, useful for cooking and easily stored) and farming lines. The farmers make pots with round bases, richly decorated, with or without colour, and less practical. The pots are made by skilful artists and they represent, perhaps, the first really symbolic and useless objects distributed for non-practical purposes (i.e. agriculture, domestic tasks). In large part this is opposite to the role of harvesting blades. But even these seem to have been deposited with their symbolic values in mind. In the burial contexts where they are mostly found, they might express the importance of agriculture (i.e. harvesting) and admission to useful resources (i.e. flint), more than their being the personal property of the deceased.

From being deposited in graves as the remains of the personal possessions of the deceased which they used in everyday tasks during the Palaeolithic and Mesolithic, the blades change designation in the Neolithic world (Fig. 20). In the Neolithic context they become representations of the "most important tasks", or the most valued: tasks brought by the ancestors, farming activities. If not in graves, they seem to have been stored carefully, with production waste separated from finished products. Viewing the treatment of blades in Neolithic contexts (from the Middle East to northern Europe), one can tell that in everyday life they were used as specialized, systematically constructed tools, and in connection with death they were important symbols, embodying the needs, wishes and desires of the surviving near and dear of the deceased.

The burial rituals which followed the spread of farming in Europe have some structural similarities,

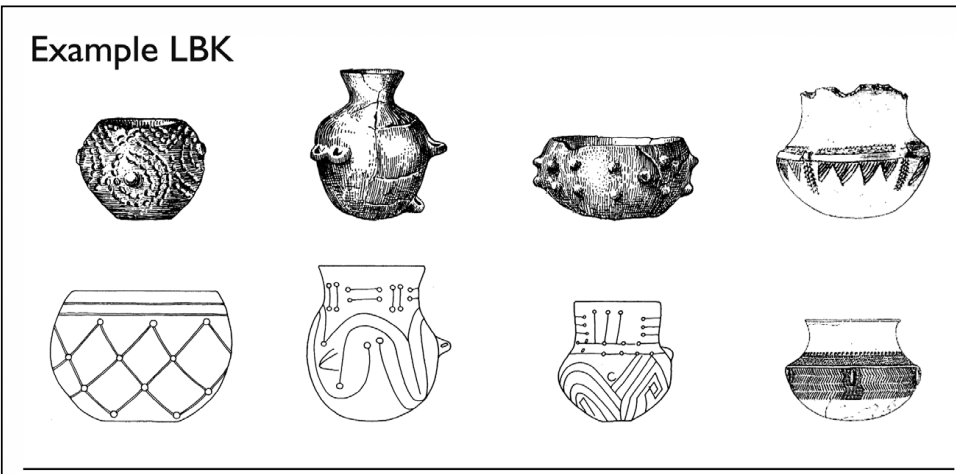

Example Sesklo

Fig. 19. Hunter-gatherers' pots and LBK/Sesklo/Dimini/StarčevoKörös pots. The forms and ornamentation types suggest different social uses of the vessels. (Compilation from Persson 1999.134, Vlachos 2002.123, Podborsky et al. 1993.79-80, Burenhult 1999.223.)

such as the crouching positions of the deceased, gender differences in their skeletal positions, the occurrence of pots and "harvesting blades". These similarities crossed the boundaries of probable ethnic entities in Europe and this makes Knutsson to believe that they were not only tools in the farming tool kit, but important metaphors of the farming idea. In Scandinavian TRB and BAC contexs (Knutsson 1999 and 2000) they seem to serve as properties in a play where the deceased in burial rituals are seen as actors in the ancestral stories. It is reasonable to see the funeral gatherings as occasions where and when the important stories of farming were repeated, as ancestral histories; as enactments of the coupling of the technical and social body-parts of the society. The graves became installations where the deceased were made to model farmers in the pantheon. In this process the blades, "the reapers", seem to have 
been important material manifestations (Fig. 21). The context of blade making and use by the Pitted Ware groups (the "heirs" of the TRB in central Scandinavia), is totally different, is totally different, related as it is to domestic production and use at settlements. As two different economic and social systems, the reproduction of the TRB and PWC social formation through public symbolism, of necessity followed two different paths. Helena Knutsson and Lars Sundström thus both see history and the past as important when cultural codes are changed and thus when a new world has to be legitimized. As the TRB farmers in southern Scandinavia formulated a new past with the settled farmer as a role model, then they probably could no longer defend their segmentary settlement ideal, the egalitarian ideology. The institutions needed to do so were now lost, also as an idealized past. In the wake of the lost egalitarian ideology the seeds of change followed, a change that may have triggered a process towards inequality. The BAC graves probably represented elite graves by means of which the elites related themselves to the ancestors by actually becoming them at death. As the Middle Neolithic changes into the Late Neolithic this process of social stratification seems to be well underway in the former TRB area of southern Scandinavia.

\section{LIVES OF AXES; LANDSCAPE OF MEN}

The social organisation of the TRB society, as interpreted by Lars Sundström above, seems to indicate, contrary to the standard view, that the Early and Middle Neolithic TRB culture actually was a material manifestation of an egalitarian ideology, rather than the first expression of social hierarchy in Scandinavia. Throughout the Neolithic this unstable, ideologically driven segmetary social organisation, as Sundström pointed out, had to invest more and more in and publicly manifest its ideology to be able to reproduce it, as exemplified by a change from the EN long barrow sites to the large MN ritual centres of the "Sarups type". The collapse of the strained TRB society at the end of the MN, probably saw the be-

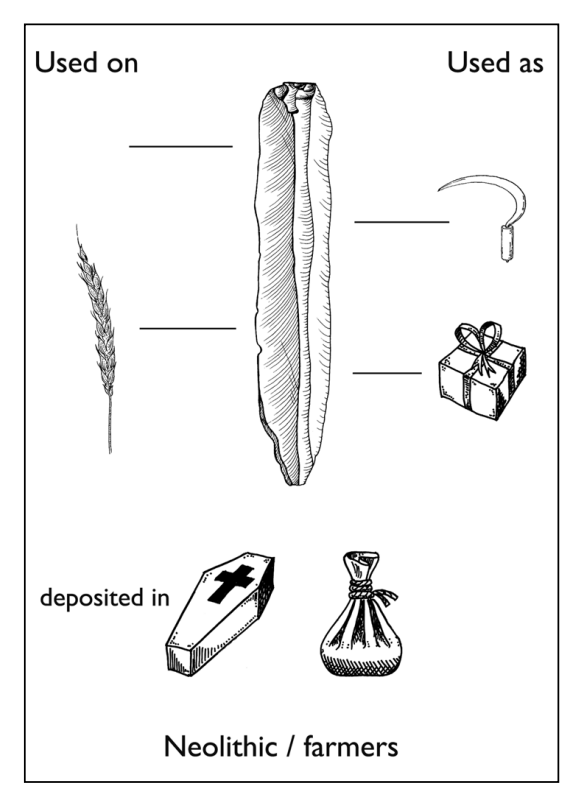
Fig. $20 A$ and B. The variable use of prismatic blades in the Mesolithic
(hunter-gatherers) and Neolithic (agricultural) societies. The find-contexts ginning of a new social order based on the notion of "the farmer" as ancestor. The Battle Axe Culture graves seem, in Helena Knutsson's study of blade and blade contexts, to be part of the reproduction of this social ideology - an ideology that might have been related to stable settlement and land ownership, thus forming the seed of change.

In an investigation of the Late Neolithic landscape and society in eastern central Sweden based on a contextual analysis of hammer axes (Fig. 22 above), Per Lekberg (2002) has shown how the political economy of a stratified society emerged as the Battle Axe Culture ideology changed around $2300 \mathrm{cal} \mathrm{BC}$. Based on the analysis of axe morphology from three different find-contexts, graves, votive offerings and settlements, Lekberg shows how the stray finds represent hammer axes at different stages of their lifehistory (Figs. 22 below, 23, 24 and 25). The life histories are thus related to variable contexts in Late Neolithic society. The dissemination of a large body of stray finds of Late Neolithic hammer axes in eastern central Sweden, representing variable contexts of action, shows that a structured cultural landscape emerges with settlements, graves and places for votive offerings (Figs. 24, 25a and b). A discussion of axe production and value further shows how simple locally produced and consumed hammer axes can be compared to more complex forms. The latter are produced at certain quarries and thus probably controlled by certain groups. These axes from quarries can be shown to have been used in ritual contexts. The interpretation is that they must have been part 
of an exchange of goods in the area, probably as part of a prestige goods economy. Lekberg can show, through a GIS application, that the different axe forms are capable of revealing not only a cultural landscape of contexts and action-spheres, but also, when mapped, a dispersal of value. This forms the basis for a discussion of the political economy and social organisation of Late Neolithic society.

The studies carried out show that there is an unequal distribution of wealth (daggers, special hammer axes, etc) in the LN cultural landscape (Fig. 25c and d), indicating the political organisation of a stratified society. The accumulation of wealth related to certain settlements and regions is interpreted with help of Marxist social theory (cf. Hayden 1995; 1998), in accordance with the concept of chiefdoms, and thus the reproduction of power through descent. The latter proposition is grounded on spatial continuities of wealth distribution in the landscape from MN B, over LN to the Early Bronze Age, manifesting the importance of descent and location. The Late Neolithic collective stone cist burials and settlements are other indications of this. The observations of collective burials in megaliths, a tension between collective and single graves, buried children in the collective graves, and the differentiation in size of houses at excavated settlements, all signal hereditary social ranking. Since house size differentiation communicates a socio-economic difference, social rank seems to have been related to an economic dimension, a social index referring to the degree of economic control.

The clustering of settlement areas, 20 by $20 \mathrm{~km}$, as shown by the distribution of stray finds (Fig. 25a and $b$ ), is interpreted as clan territories, each controlled by a hereditary elite. The accumulation of exotica and valuables in the core areas indicates further that these elites were internationally connected. Elites use different tools in creating and upholding their status and otherness. One of these is the establishing and upholding of contacts with realms unattainable to ordinary people. The exotic goods found in the Late Neolithic core areas may have been used, through display, to legitimize their right to dominate and accumulate. They probably thereby controlled the way the world was understood, by a genealogical reference to gods and other important members of the pantheon in their myth of origin. In Per Lekberg's thesis the elites' control of important aspects of the reproduction of cultural codes was carried by reference to distant tracts, materialised through exchanged valuables from a wide social setting in $\mathrm{Eu}-$ rope. A wider European outlook thus seems to pro-

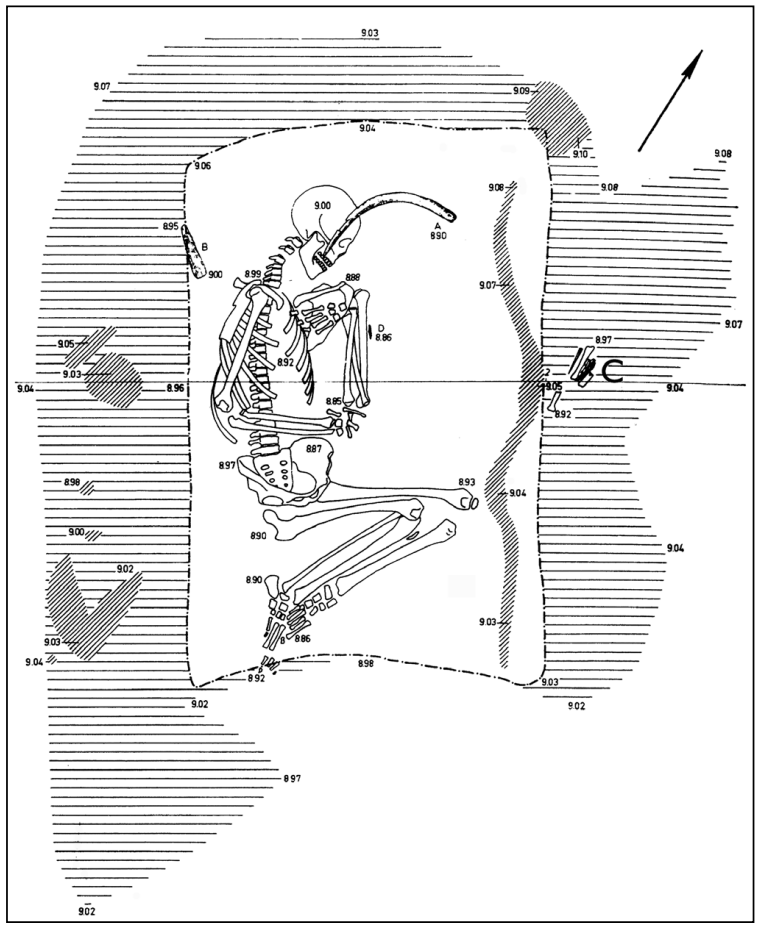

Fig. 21. A Battle Axe Culture grave. The uniformity of grave goods and grave structure from this period indicates that the ritual was formed by and steered by a common narrative. This may be due to the use of the burial occasion to manifest a social position defined as an actor in the myths "explaining the world" in this culture. In the grave ritual the person reproduced its position by reference to the ancestral past (after Malmer 1975.Fig 36).

vide the axe hammers, as well as Scandinavian Late Neolithic society as a whole, with Bronze Age contexts of Pan-European contacts, possibly based upon earlier Corded Ware Culture networks of interaction. This latter proposition is well in line with the discussion of large-scale networks already in the Middle Neolithic shown by Helena Knutsson (2001).

\section{DAGGERS, KNOWLEDGE AND POWER}

Per Lekberg's study of the contexts of hammer axes showed a Late Neolithic stratified society with a power structure based on descent, and thus by definition a type of "chiefdom". Elites in such stratified societies reproduce their power through, among other things, the display of wealth. To archaeologists this is seen as a precondition for craft specialization (Olausson 1998) and thus formed the ground for the development of groups of people that produce these display goods. One such display item of the Late Neolithic society, the flint dagger, has been discussed by Jan Apel within the coast to coast project. He uses the production and consumption pattern of 
the dagger to elucidate questions of craft specialization and thus social structure in the LN society. The provenience of the Scandinavian daggers has been well known for along time, and their secondary spread indicates exchange networks spanning the southern part of Scandinavia and in general terms respecting the age old border between the huntergatherers to the north of Limes Norrlandicus and farmers to the south (Fig. 26). The late Neolithic networks thus bear heavily on the historical structures from which it was once born.

The flint daggers were produced in several of the Danish flint mining areas (Fig. 30). Since they were seen by archaeologists as inciting/ instigating objects, all possible analyses of them have been made, chronologies, geographies of production schemes, and so on. But an overall picture of the growth of knowledge and development of technology has been missing. To achieve this, Apel cooperated with a skilful flint-knapper, Errett Callahan, of Lynchburg in Virginia (Apel 2001). Callahan and Apel mapped the

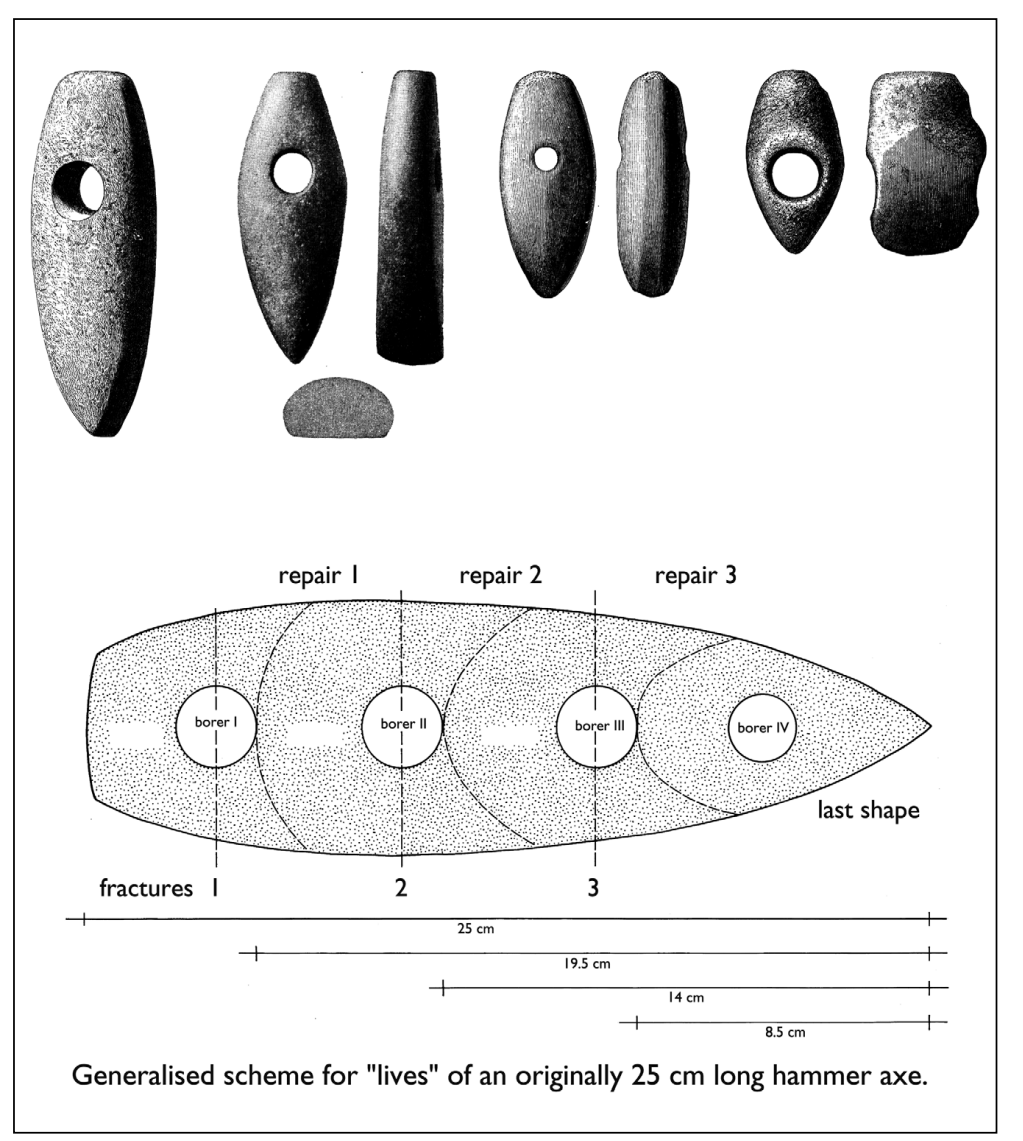

Fig. 22. Shaft hole axes, or hammer axes from Swedish Late Neolithic period and their assumed "life history". At different stages of its life the axe was ritually deposited in different settings. The long unused axe was deposited in caches, the short, used axes in graves and the broken axes in settlements. The stray found axes thus gives a picture of the Late Neolithic cultural landscape. procedures of all the processes involved in the production of the Danish types of daggers. They divided the process of production into steps, with different degrees of skill needed (Fig. 27). Based on this division, Apel could see that an apprenticeship system was needed to transmit the knowledge (theoretical part) and the know-how (practical, internalised physical part) of the production of these prestige objects. The social theory explaining and exploring the role of knowledge in power struggles is applied and compared with the patterns of production. Apel, as did Lekberg earlier, thus interprets Late Neolithic society as the first Scandinavian society in which power is inherited and knowledge is transmitted within family groups and guarded as a family possession.

From the analysis of knapping debitage in the flintrich areas and close to flint mines in Denmark it was possible to deduce that learning processes were accomplished partly in secluded places. The production of daggers was performed in different places, depending on the availability of flint (Fig. 30), as well as the degree of know-how needed in the production stage. Those parts of production processes which needed a low degree of know-how were conducted in seclusion, often close to the sources of raw material. The difficult parts of production, which demanded high skills, were carried out publicly, in the settlement sites. Apel interpret the latter as performances, or public manifestations of knowledge, tradition and history and probably status of the flint knappers whereas the hidden production of the simpler and easily replicated stages is seen as a way of controlling knowledge. In those parts of Scandinavia that were distant from flint sources (Fig. 26), for example the area of eastern central Sweden, no production of daggers at all is documented although thousands of readymade daggers exist there. The debitage found at the settlements however shows that the daggers, or, other large bifacial tools (like sickles and spear heads) were resharpened in an amateurish way. Moreover, one special type of dagger production debitage was imported from southern Scandi- 
navia, bifacial thinning-flakes. They were locally transformed into arrowheads through a simple pressure technique (Fig. 28). The interpretation is that the imported flakes and tools where knapped by non-professional knappers, that they had a high symbolic value, which was manifested among other things in their role as burial objects and that the Late Neolithic society outside the flint areas, actually needed these flint items to be able to reproduce central categories of its ideology among other things in burial rituals

In Helena Knutsson's work above it was said that the burial ritual of the battleaxe culture may have been a dramatization of parts of the culture bearing myths. The dead personified some of the actors in it and the tools, for example the flint blade sickle, was important symbols in the construction of the ancestral individual, relating him or her to farming. In the Battle axe culture the ancestors had thus according to this interpretation become farmers. Apart from flint blades (see Fig. 21) the bow and arrow and above all the battleaxe was an important metaphor in the battle Axe Culture indicating a relationship to warfare. In the Middle Neolithic/Late Neolithic transition in southern Scandinavia flint daggers seem to have replaced the battleaxe as the principal male prestige weapon. Modifications in social functions and symbolic meaning, probably accompanied the material shift, which was linked to the creation of an attractive masculine identity. In the Battle Axe Culture every man, at least in elite groups, was a warrior. Maleness was simply synonymous with a social being as warrior (Vandkilde 2000.39). In the Beaker affiliated Late Neolithic period, discussed by Jan Apel, the warrior role has apparently become slightly more privileged as we see a variation in grave types and wealth put in them. To be a warrior possibly implicated membership of a brotherhood of warriors who occupied the peak of the social hierarchy of prestige. In eastern central Sweden we see the development of social stratification as expressed in the landscape as shown by Per Lekberg in his work. Although the "clan territory" do not coincide to well with the deposition of daggers (Fig. 25b), it might be that the reproduction of the social structure in the area was carried out at ancestral places where the flint dagger, the flint flake, the bifacial flint point - all imported goods - where used as insignia of "the warrior", a warrior that was part of the myths relating the present social structure to ancestral beings. Jan Apel interprets this behaviour in terms of a concept brought into anthropology by Maurice Bloch - the past in the present. It is to be understood as a description of the use of tradition and history in daily life and tasks and in social power struggles. The idea of the warrior, a European theme at this time (Fig. 29), seems have been one important institution in this process, as shown by the need to have all the necessary gear: dagger, bow, etc. The craft specialization attached to dagger production as suggested by Apel, is commensurate with such a social formation.

A detailed analysis of the chronological scheme of the daggers by Ebbe Lomborg, presented earlier and supported by critical investigations made by other 


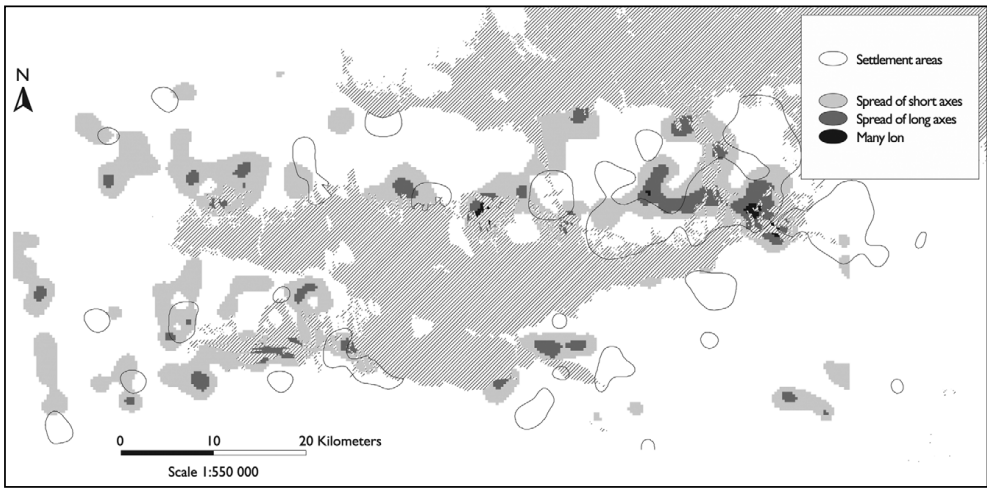

Fig. 24. Lekbergs study area around lake Hjälmaren and north-eastern Uppland. The Late Neolithic cultural landscape as shown by the spread of axes of different life histories and thus size. The dark areas mark ritual centres where long axe has been deposited. The grey areas probably represent areas with graves.

researchers, is an important section of the book. Detailed comparisons, combined with radiometric datings made in 1989 (Vandkilde 1989) show that if we accept the groups presented by Lomborg, we have to understand them more in terms of regional differences than in chronological sequences. Elaborating on this theme, Jan Apel suggest that we can trace two separate dagger production areas within the Danish flint bearing districts. They develop in the beginning of the Late Neolithic, one in the Limfjord area on Jutland, the other in the east, on Danish islands and in south western Scania. In a rough scheme the so-called type I daggers were produced in the western mines, and type II-III daggers were produced in the east (Fig. 30). He also took on the task of mapping the distribution of Danish daggers, in an a attempt to reconstruct distribution routes, consumption habits and patterns. A detailed mapping of the daggers found outside the flint areas, i.e. the production sites, shows that the spread of finished products was directed along two main routes to northern Scandinavia. The Jutland products were distributed along the western route, mainly to western Norway and northern Sweden. The Jutland producers seem to have exported their daggers also along the south eastern Baltic coast and to eastern central Europe. The island daggers were mainly distributed to southern Sweden and south eastern Norway along some eastern routes, but they were also traded to western central and western Europe (Fig. 30).

Daggers were produced in the marginal areas of Denmark, i.e. the least productive agricultural zones. As a matter of fact, these areas seem to have been abandoned in the preceding periods. The production of daggers, i.e. the availability of suitable raw materials, made the area attractive to settlers during the early
Late Neolithic. Production flourished over 400 years. Around $1950 \mathrm{BC}$, the influx of bronze objects into the areas of dagger consumers made the flint knapping groups more or less obsolete. At least the western producers in Jutland seem to have lost their position. The eastern producers designed forms in flint which imitated the imported bronze goods. They contiued production into times which are normally attributed to the Early Bronze Age.

In summary, Apel views the society of the Late Neolithic in Scandinavia as well-organized in patrilineal structures. Chieftain lineages controlled the most productive agricultural land, and in marginal areas groups exercised power over the available resources such as flint. Here, the groups specialized in the extraction of wealth from these resources and traded them for agricultural products as well as access to power. The knowledge of the profession seems to have been guarded and passed down along lineage lines. When flint as a raw material for prestige objects went out of fashion, the status of the dagger producer lineages vanished.

\section{THE LURE OF ORIGINS - A COMMENTED CRI- TIQUE}

A classic storyline in the form of an evolutionary process from egalitarian hunter-gatherers in the Mesolithic to chiefdoms in the late Neolithic has been presented in the paper, albeit in a scientific vocabulary. The forces of change have been related to a continuous process of increasing conflict between structure and praxis, between past and present. Since this may be called a process of structuration, we have set the focus on history as a force in the construction and reproduction of social ideologies, a past communicated through material symbolism continously reinterpreted to suit the present. As archaeologists we also reuse the past to make the present logic to our world view. The writing of a history of origins for our present-day society always in some respect has to make this process seem continuous and logical. This problem of the backward gaze has both social and psychological implications. Pierre Bourdieu has seen this in peoples' process of constructing personal narratives; Norbert Elias sees the process as formed by evolutionary thinking in general. 
In one of the PhD projects attached to the project, Per Johansson in a critical evaluation of archaeological writing on Neolithization, among other things addresses just this problem: the psychology of writing the past into the present. One could perhaps say that he sees the work of the archaeologist partly as we have seen the Mesolithic and Neolithic populations of Scandinavia, Johansson studied the interpretation of the material remains of central Sweden and discussed the discrepancy between the focus on Neolithization (i.e. the import of the agricultural idea, people, or techniques) and the actual lack of material remains which would support the view of a massive change during this time ( $\mathrm{Jo}$ hansson 2003). The early appearance of agriculture has been supported by very little material evidence, Johansson argues. The burden of proof lies mostly in secondarily associated materials and material changes. It is of course a pedagogical problem for archaeology that the presentation of these secondary connections has not been made clear enough. The first analysed relation is that between the distribution of axes and farming. Here, the problem is that the axes seem to have been used as a reinforcement of other, natural farming indicators. It is noted that the form of farming archaeologists are expect in the area is swidden cultivation, "primitive" enough to be accepted as a primeval agricultural method in the region. The arguments for connecting axes with agriculture are weak, and support for the interpretation of early agriculture as swidden cultivation is so far almost non-existent.

From the vegetation analyses it is obvious that forests have been cleared since at least Late Mesolithic, and that the clearings were intensified during the EN. The development (or introduction) of either domesticated (imported) species or endemic (wild) plants is discussed in connection with this. The fact is observed that archaeologists are still missing instruments for the classification of domestication, es- pecially when it comes to endemic, originally wild species (this applies also to animal species, like wild boar and deer). The concept of "caring for" is brought into the discussion here. It is, however, difficult to bring together the making of clearings and the occurrence of agriculture. From this point of view, Johansson means, the dating of domestication to around $4000 \mathrm{BC}$ seems arbitrary. It is beyond doubt that in the first part of the Neolithic period there were changes in habitation structure both within the sites and in the settlement of the landscape. As 
we understand from Johansson's critique, we have not been able to explain the changes very clearly. The problem which he calls the coast/inland problem is a good example of this. The pattern which appeared around $4000 \mathrm{BC}$, when excavated, is distinctively different from the former Mesolithic period, and this difference appears clearly first in the combination of the details making the pattern. However, we are still bound to analyse the individual parts of this pattern. We think that in the discussion we lose the pedagogical line and strength of explanation (we could say that what is obvious to archaeologists is not mentioned in the discussion, since there is agreement on that; this then disappears from the eyes of the outside reader). In this case, the pattern of sites and the differences within them are obvious to all archaeologists. The coastal sites preserve, as is obvious from radiocarbon dates, Mesolithic patterns into the Neolithic, concerning the shape of dwellings, faunal remains and the site chosen for occupation. They display similarities in the pattern of artefacts, such as the occurrence of pots, polished thin-butted axes and some appearances of domesticated species. But they also have individual characteristics, for example in pottery decoration styles and burial customs, and this pattern also occurs within the group of coastal sites dated to the Neolithic. The socalled inland sites have their own patterns, comparable in the same way. They display a special intra-site organisation, with solitary long-houses, sometimes a few generations of them on the same spot. They show a dominance of domesticated species among the ecofacts; they have pots with characters which link them together, but separate them from the nearest coastal sites, and so far they lack traces of funerals. Since all these observations are relatively recent, they are of course submitted to critical discussion within the archaeological community, and this make the interpretation of them a little "un-transparent".

Per Johansson also touches upon the essence of archaeological concepts of the Funnel Beaker Culture and the Pitted Ware Culture. He correctly points out

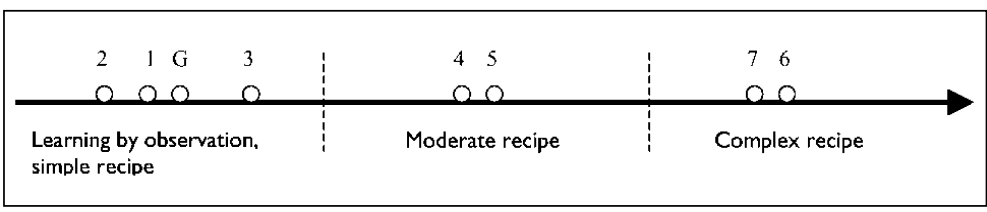

Fig. 27. The seven production stages defined by Callahan (and a grinding stage G), graded according to the degree of theoretical knowledge. Apel assumes depending on find context for these different stages that the easier stages where the performed in secluded places, the stages needing more know-how within the settlement sites. This is seen as a social strategy.

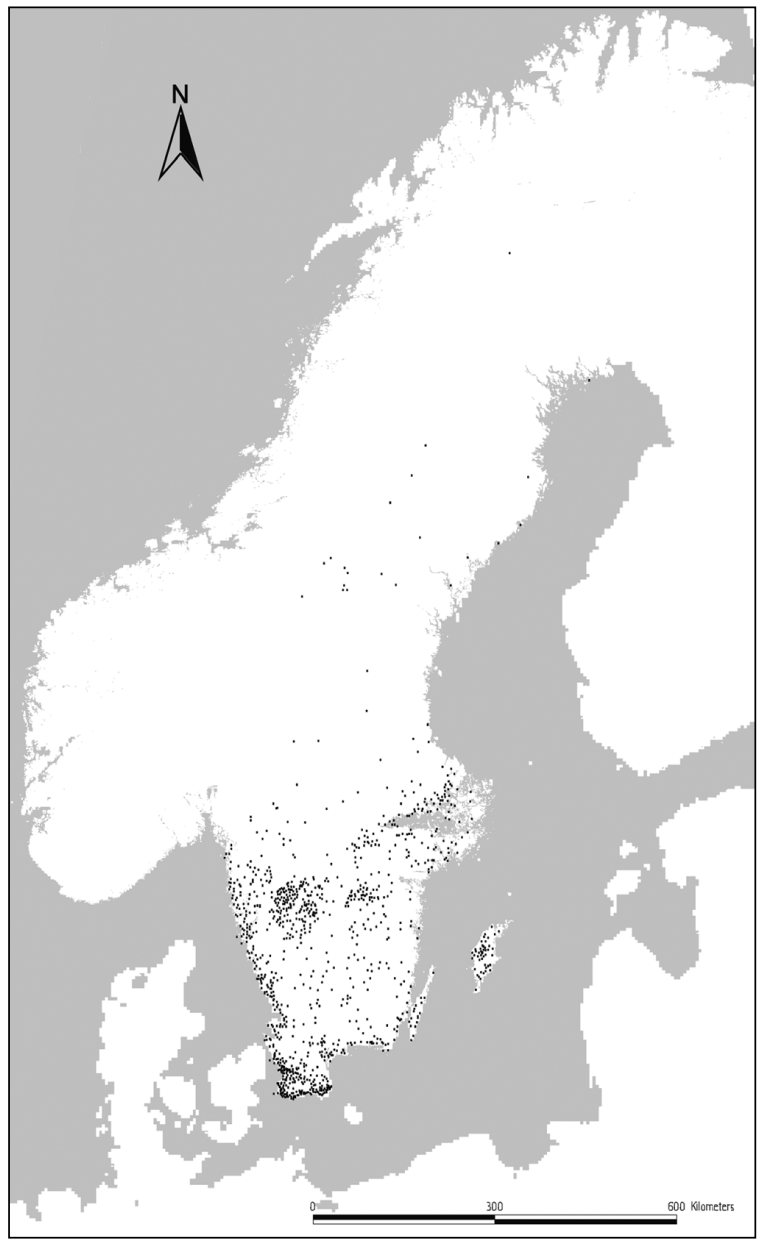

Fig. 26. The distribution of flint daggers in Sweden. Note the structural relationship between the Late Neolithic and the earlier TRB culture.

the incongruities and the debate about their meaning, but his words reveal another of the weaknesses of archaeology as used in public contexts. Because of its very complexity, archaeology often presents its interpretations in the form of narratives. These narratives have many extrapolations between a few known points. In recent decades these narratives captured some parts of the "inner field" of archaeology, where, rightly, Johansson expects methodologically and theoretically grounded scientific debate. Many of the postulates that he picks up from different archaeological works are no more than loosely proposed ideas often grounded on impressions, and not thorough analyses of all the available material. These proposals are, of course, subjected to critical scrutiny, often in the form of oral debates which in many cases are not published. In the end, the visible results found by the outside visitor to archaeology are loose ends in the form 


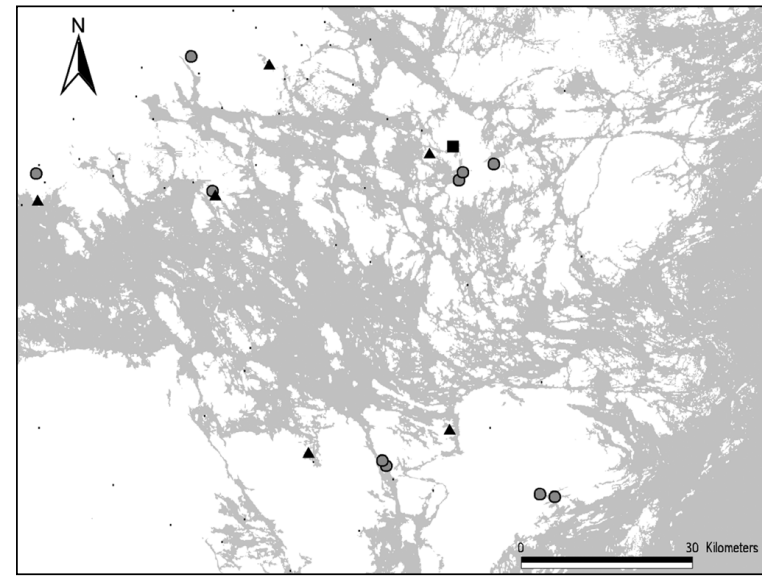

Fig. 28A. Excavated Late Neolithic sites in eastern central Sweden. Settlements are marked by circles, gallery graves by triangles and the ritual depositions by a square.

of "scientific statements". This is the case with propositions of the non-existence of Pitted Ware Culture, or differences in the Neolithisation process in western central Sweden. These are impressions which turn into probabilities, and they have a tendency to turn into truths the further from archaeological discussion they appear. In addition, in these cases archaeology has itself to blame, for not being explicit in its demands on arguments for the proposals presented. Johansson points out two other important discussions. One concerns the time schedule of the appearance and development of complexity in the Stone Age. This discussion in archaeology, according to our view, has suffered from the implicit social evolutionism inherent in archaeological thought, which Johansson discerns elsewhere. Complexity is simply expected to increase in the course of the Stone Age, and interpretations of "cultures" have been adjusted to these expectations, even in the modern debate on Neolithisation.

The other discussion concerns the real evidence of the artefacts about prehistoric peoples' lives. This discussion, as Johansson points out, is vivid in archaeology. One part concerns interpretations of the present, and the missing artefacts; the other concerns the symbolism of the remains. Here, the discussion was especially hot after the presentations of English archaeologists maintaining the polarity of the wild and the tame (or domus and agrios, as named by Hodder (1990)). Per Johansson detects the archaeologists' decision to argue along these (partly structuralist) lines, and he also detects the missing burden of proof for it. Here, the narrative aspect of archaeology again invades scientific thinking. The problem of the initially scarce traces of agricultural

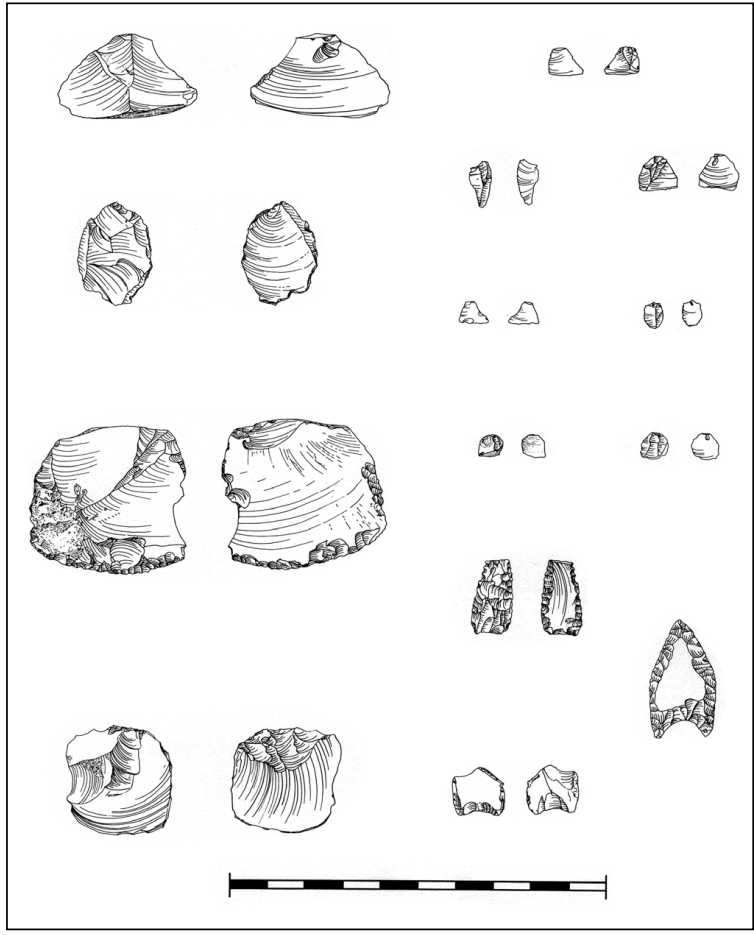

Fig. 28B. Different types of production debitage and formally defined artefacts of imported flint found at Late Neolithic site in eastern central Sweden.

techniques and living habits (i.e. what we today define as belonging to agriculture, heavily dependant on anthropological analogies, not to say parallels) is solved by pointing out as more important the changes in ideology that supported the continuation into the age of agriculture, which Johansson calls circular arguments. He points out the paradox of archaeology, in which arguments still surround the opinion that more artefacts are equal to more complexity, which means a more developed culture. This is nonsense, but is also the state of much of archaeology today, as it is presented to the public. The solution to these problems would be to detach archaeological interpretation from its inherent idea of explaining the origins of today's society, Johansson suggests. We have to see the importance of comparisons of different ways of life, not to judge them, at least, lives already past. And not presenting them only as "historically rooted historical roots" of the paths our cultures are following. Johansson says all developments or changes also have a present aspect which we cannot find in looking backwards. The same is applicable to the views of past cultures. He shows that the search for origins lures us to see what needs to be seen in prehistory; and we have to admit that he is right. But in a very special way, this desire, at least as we feel it, is the way in which archaeology fulfils the expectations of our modern society, and archaeo- 
logists must, in our opinion, participate in the social and political debate in society, showing exactly this problem and changing the path of this desire.

\section{SO... WHO WHERE THE ANCESTORS?}

Emile Durkheim, the French sociologist, once argued that religion was for pre-modern society what science is for the modern world. Both institutions "explain the world" and thus have ontological status. At the core of identity in every society there are myths of origins, narratives of a place from where the people originated, narratives of ancestors, founding fathers or mothers, and, pantheons of gods. The world and its inhabitants are thus explained with reference to origins, whether it is the Garden of Eden, the story of The Big Serpent, or Lucy and Big Bang. As cultural codes are questioned and societies live through paradigmatic change, as must have been the case in Scandinavia in the Late Stone Age, then these stories reproducing society must have changed to accommodate to the new "paradigm" or world-view. The important question to ask then is: "Who where the ancestors". In the Coast to Coast project, this may be seen as one of the recurring themes in the explanation of the material representations of social reproduction in Scandinavia during the Stone Age and thus active in the process of Neolithization. This explanation of cultural change is well in line with our attempt to downplay materiali-

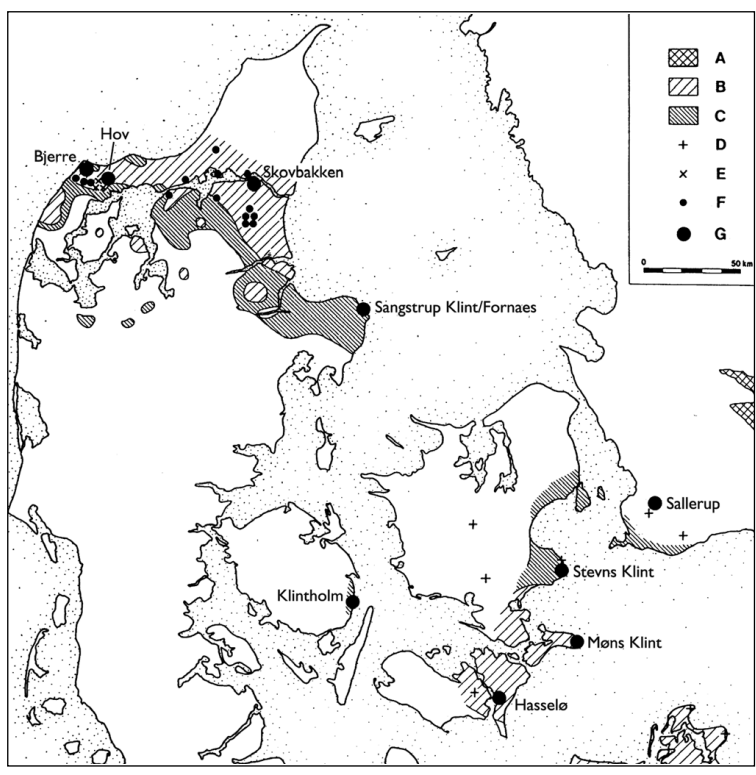

Fig. 30A. The natural occurrence of flint in southern Scandinavia. In this area the daggers where produced that later, through exchange networks where distributed to eastern central Sweden (compare Fig. 26).

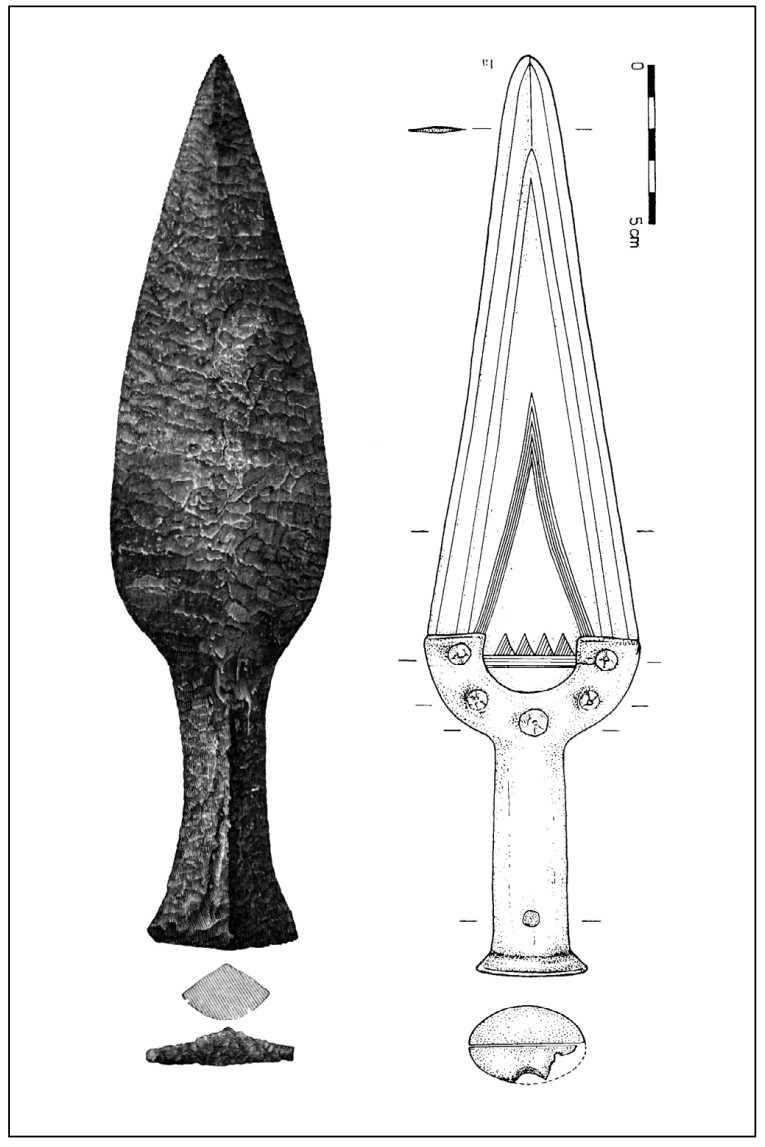

Fig. 29. A prestige weapon used in rituals in the Late Neolithic. The Scandinavian daggers presumably copied Unetice bronze dagger and may very well have been part of a similar "warrior ideology" at this time. In this paper we assume that they also where actors in ritual plays where the important narratives of ancestral deeds where told.

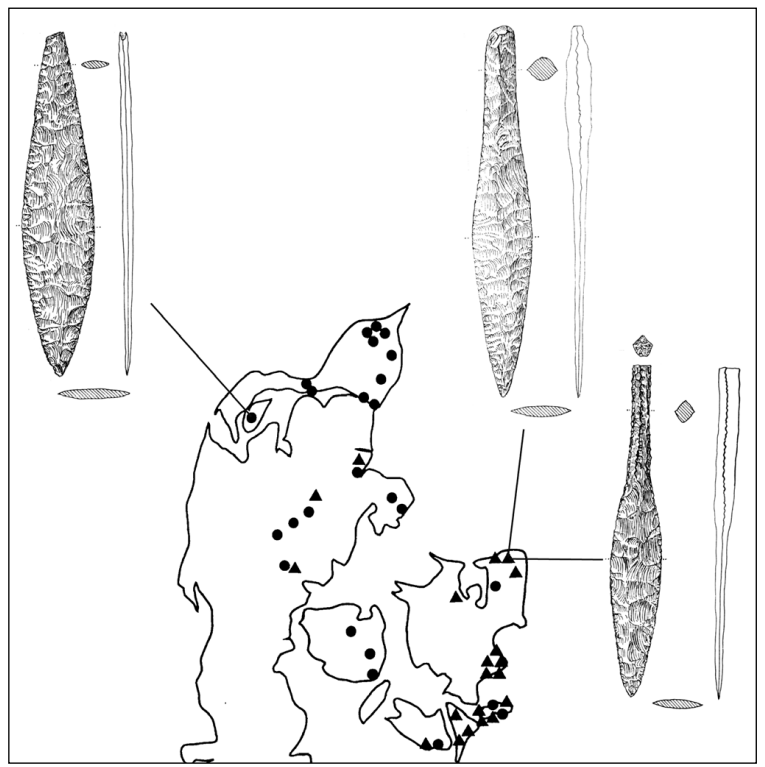

Fig. 30B. The distribution of dagger hoards in Denmark. The hoarding mainly took place in the flint bearing areas. 


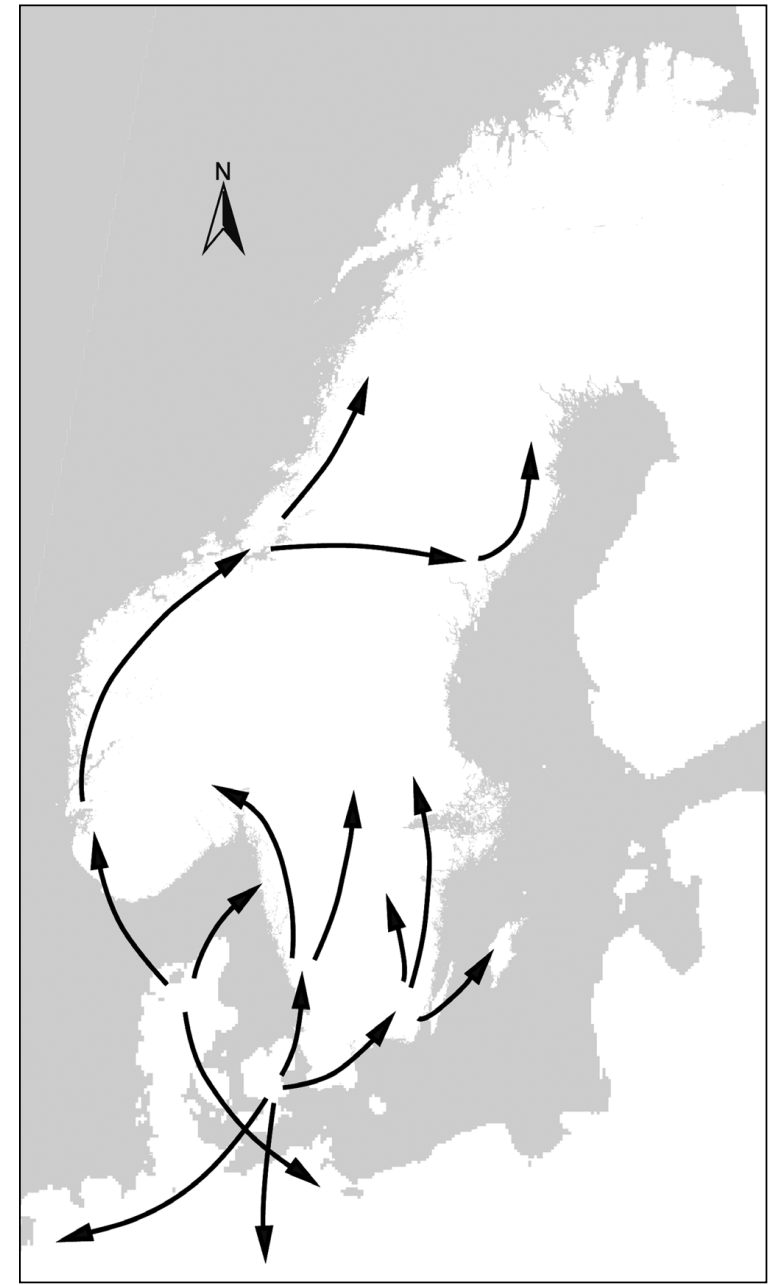

Fig. 31. Exchange routes from the two main production areas to different parts of Scandinavia during the late Neolithic.

stic explanations of cultural change within the Coast to Coast project in general.

We have shown how the tension created within the age-old old hunter-gatherer networks in Scandinavia as Neolithic life ways where introduced, could be resolved by redefining identity and thereby defining a new "origin" as illustrated by public symbolism in the form of the adoption of new technologies and raw-material use in the north. As the Neolithic as we know it (TRB) was introduced in southern and central Scandinavia, the past was further made active during rituals at the coastal hunting stations as a way of creating a defence of the old egalitarian ways of life by way of an idealized past. As tensions between daily praxis and the ideology within the segmentary and thus vulnerable TRB society became too great in the Middle Neolithic, the past was brought in as a saver again. Now the past was once again rewritten to suit the present; the ancestors and thus the "model life" became "the farmer". Gra- ves became installations, materializations of the important narratives of the past. Other aspects important in the understanding of cultural change discussed in the project have been tension in gender roles and how they may have been activated and thus important in the process of change. We have seen them played out and materialized in daily routines on settlement sites by the work of Hallgren, Lindgren and Lidström-Holmberg. A discussion of the occurrence of marked, spatial structures, with spatially separated activity areas mimicking special men's houses are discussed in relation to post-marital rules of residence and descent and thus social organisation in the TRB. We have also discussed how a fertility cult in sacrificial fens related to the early TRB inland farmsteads seems to have paralleled the social structures on the settlements. Here, the grinding tools two parts were metaphorical actors in a ritual that must have had its narrative counterparts.

The idea of "the farmer" that was founded in the late Middle Neolithic as evidenced in grave rituals must at the same time have brought with it the final blow to egalitarian institutions, paving the way for struggle for power in the Scandinavian area at the time. In the project a discussion by Apel and Lekberg of the political economy of the late Neolithic in southern and central Scandinavia indicates the development of a hereditary political organization as shown by crafts specialization, unequal access to and spatial continuities in the accumulation of wealth. Also, the grave rituals were manifestations of the power structure by reference to cultural heroes (specially designed sets of gear, such as daggers, hammer axes etc) that must have been part of the narratives that "explained the world" at that time.

The evolutionary sequence as presented above produced by the group of researchers in the Coast to Coast project no doubt follows closely the common interpretations of change from the Mesolithic to the Late Neolithic. It explains in a process from the simple to the complex the history of the present, created by a series of important events, like for example Neolithization. We have put emphasis on the importance of historicity in this process, thereby somehow naturalising our own activity as archaeologists. The past has always been returned to and made active in socio-political processes, the modern world we live in is no exception. 


\section{REFERENCES}

APEL J. 2001. Daggers, Power and Knowledge. Coast to Coast Books No 3. Uppsala.

APEL J. BÄCKSTRÖM Y., HALLGREM F., KNUTSSON K., LEKBERG P., OLSSON E., STEINECKE M. and SUNDSTRÖM L. 1995. Fågelbacken och trattbägarsamhället. Tor 27. Uppsala: 47-132.

BURENHULT G. 1999. (ed.) Arkeologi i Norden 1. Stockholm.

CHI Z. 2002. The discovery of early pottery in China. In M. Budja (ed.), Documenta Praehistorica XXIX. 9th Neolithic Studies: 29-36.

DEMOULE J.P., PERLÈS C. 1993. The Greek Neolithic: A New Review. Journal of World Prehistory Vol. 7, No. 4. 355- 416.

HALLGREN F. 1996. Sociala territorier och exogamirelationer I senmesolitisk tid. Tor 28 Uppsala: 5-28.

HALLGREN F., DJERW U., AF GEIJERSTAM M. and STEINECKE M. 1997. Skogsmossen, An Early Neolithic settlement site and sacrificial fen in the northern borderland of the Funnel-beaker Culture. Tor 29. Uppsala: 49-112.

HALLGREN F. and POSSNERT G. 1997. Pottery design and time. Tor 29. Uppsala: 113-136.

HALLGREN F. 1998. Etnicitet under stenåldern i Mellansverige och Södra Norrland. In B. Johnsen and S. Welinder (eds.), Etnicitet eller kultur. Östersund: 61-77.

2001. Lineage Identity and Pottery Design. In Olausson D. and Vankilde H. (eds.), Form-Function-Context. Lund: 173-191.

2002. My place or yours? In Larsson L., Kindgren H., Knutsson K., Loeffler D. and Åkerlund A. (eds.), Mesolithic on the Move: 592-599.

HAYDEN B. 1995. Pathways to power: Principes for creating socioeconomic inequalities. In Price T. D. and Feinman G. (eds.), Foundations of Social Inequality: 15-85.

1998. Practical and Prestige Technologies: The Evolution of Material Systems. Journal of Archaeological Method and Theory. Vol 5. No 1: 1-53.
HODDER I. 1990. The Domestication of Europe. 0xford.

JOHANSSON P. 2003. The Lure of Origins. Coast to Coast Books No 8. Uppsala.

KNUTSSON K., LINDGREN C., HALLGREN F. and BJÖRCK N. 1999. The Mesolithic in Eastern Central Sweden. In Boas J. (ed.), The Mesolithic in central Scandinavia. Ny rekke. Nr. 22: 87-123.

KNUTSSON K. and MELCHERT P. (manuscript). Skumparberget I. A Mesolithic hunting stand. In Apel J., Y. Bäckström, C. Hadevik, K. Knutsson, A. Kritz, E. Kars, H. Kars, P. Lekberg, P. Melchert, M-L. Nilsson and L. Sundström (eds.), Skumparberget I och II. En meslitisk aktivitetsyta och tidigneolitiska trattbägarlokaler vid Skumparberget $i$ Glanshammars sn, Örebro län, Närke. Rapporter från Arkeologikonsult AB. Upplands-Väsby.

KNUTSSON K., FALKENSTRÖM P. and LINDBERG K-F. 2003. Appropriation of the Past. In Larsson L., Kindgren H., Knutsson K., Loeffler D. and Akerlund A. (eds.), Mesolithic on the Move.

KNUTSSON H., 1999. Two Technologies, Two Mentalities. In Linda R. Owen and Martin Porr (eds.), Ethno-Analogy and the Reconstruction of Prehistoric Artefact Use and Production. Urgeschichtiche Materialhefte 14. Mo Vince Verlag. Tübingen: 53-74.

2001. Technology, mythology and the travels of the agricultural package in Europe. In M. Budja (ed.), Documenta Praehistorica XXVIII. $8^{\text {th }}$ Neolithic Studies: 117-132.

KOZŁOWSKI S. K. 1999. The Eastern Wing of the Fertile Crescent: Late Prehistory of Greater Mesopotamian Lithic Industries. BAR International series 760.

KUZMIN Y. V. 2002. The earliest centres of pottery origin in the Russian Far East and Siberia: review of chronology for the oldest Neolithic cultures. In M. Budja (ed.), Documenta Praehistorica XXIX. 9th Neolithic Studies: 37-46.

LEKBERG P. 2002. Yxors liv, människors landskap. Coast to Coast Books No 5. Uppsala. 
LIDSTRÖM-HOLMBERG C. 1998. Prehistoric Grinding Tools as Metaphorical Traces of the Past. Current Swedish Archaeology, Vol. 6. Stockholm: 123-142.

(in press). Feminist critique on the worth of words. Inquiries into Early Neolithic gendered Querntechnology. In Damm C. and Engelstad E. (eds.), Womens worlds. Revisiting the Past. Tromsö.

LINDGREN C. 1999. Material culture and site variability. L'Europe des derniers chasseurs, 5 e Colloque international UISPP, 18-23 septembre 1995: 367375.

LINDGREN et al 1997. My way or your way. On the social dimension of technology as seen in the lithic strategies in eastern middle Sweden during the Mesolithic. 2003. In Larsson L., Kindgren H., Knutsson K., Loeffler D. and Åkerlund A. (eds.), Mesolithic on the Move. Oxbow books. Oxford: 177-183.

OLAUSSON D. 1998. Battleaxes: Home-made, made to Order or Factory Products? In Holm L. \& Knutsson K. (eds.), Third Flint Alternatives Conference at Uppsala. OPIA 16: 125-140.

ÖZDOGAN M. and BASGELEN N. 1999. Neolithic in Turkey. The craddle of civilization. New discoveries. Ancient Anatolian Civilizations Series: 3. Istanbul.

PERLÈS C. and VITELLI K. D. 1999. Craft Specialization in the Neolithic of Greece. In Halstead P. (ed.), Neolithic Society in Greece. Sheffield studies in Aegean archaeology: 96-107.

PERSSON P. 1999. Neolitikums början. Coast to coast Books No 1. Göteborg.
PODBORSKÝ V. and collective 1993. Pravěké dějiny Moravy. Vlastivěda Moravská. Země a lid. Nová rada. Svazek 3. Brno.

SALOMONSSON B. 1955. A Closed Find of Fifteen Flint Blades. Meddelanden från Lunds Universitets Historiska Museum: 205-212.

SJÖGREN K. G. 2003. "Mångfalldige uhrminnes grafvar..." Megalitgravar och samhälle $i$ Västsverige. Göteborg

SUNDSTRÖM L. 2003. Det hotade kollektivet. Coast to Coast Books No 6. Uppsala.

VANDKILDE H. 1989. Det aeldste metalmiljö i Danmark. In Poulsen J. (ed.), Regionale förhold in nordisk Bronzealder. 5. Nordiske Symposium for Bronzealdersforskning på Sandbjerg Slot 1987. Jysk Archaeologisk Selskab Skrifter XXIV: 29-46.

- Material Culture and Scandinavian Archaeology: A Rewiew of the Concepts of Form, Function and Context. In D. Olausson and H. Vandkilde (eds.), Form, Function and Context. Material culture studies in Scandinavian archaeology: 3-50.

WELINDER S. 1998. Del 1. Neoliticum - Bronsålder 3900 - 500 f. Kr. In Welider S., Pedersen E. A. and Wigren M. (eds.), Jordbrukets första femtusen år 4000 f. Kr. - 1000 e. Kr. Stockholm: 11 - 236.

VLACHOS D. 2002. Changes in the production and use of pottery from the Early Neolithic to the 'secondary products revolution': some evidence from LN Makriyalos, Northern Greece. Documenta Praehistorica XXIX. 9th Neolithic studies: 119-126. 